\title{
Rapid Morphologic and Molecular Activation of Microglial Cells by Stimulation of the P2X7 Receptor Correlates with Neuron Loss
}

\section{Keith E Campagno}

University of Pennsylvania

\section{Wennan Lu}

University of Pennsylvania

Assraa Hassan Jassim

University of Pennsylvania

\section{Farraj Albalawi}

King Saud bin Abdulaziz University for Health Sciences

\section{Aurora Cenaj}

University of Pennsylvania

\section{Huen-Yee Tso}

University of Pennsylvania

\section{Sophia P Clark}

University of Pennsylvania

\section{Sripinun Puttipong}

University of Pennsylvania

Néstor Más Gómez

University of Pennsylvania

Claire H Mitchell ( $\nabla$ chm@upenn.edu )

University of Pennsylvania https://orcid.org/0000-0002-9784-6672

\section{Research Article}

Keywords: Microglial activation, P2X7 receptor, neuroinflammation, mechanical strain, IL-1 $\beta$, NLRP3 inflammasome, Sholl analysis, migration

Posted Date: April 21st, 2021

DOl: https://doi.org/10.21203/rs.3.rs-424697/v1

License: (c) (1) This work is licensed under a Creative Commons Attribution 4.0 International License. 

1 Title: Rapid morphologic and molecular activation of microglial cells by stimulation of the P2X7

2 receptor correlates with increased pressure and neuronal loss

3 Authors: Keith Campagno ${ }^{1}$, Wennan $\mathrm{Lu}^{1}$, Assraa Hassan Jassim ${ }^{1}$, Farraj Albalawi ${ }^{4,5,6}$, Aurora 4 Cenaj $^{1}$, Huen-Yee Tso ${ }^{1}$, Sophia P. Clark ${ }^{1}$, Puttipong Sripinun ${ }^{4}$ Néstor Más Gómez ${ }^{1}$, Claire H. $5 \quad$ Mitchell $1-3$

6 Address: Departments of ${ }^{1}$ Basic and Translational Science, Anatomy and Cell Biology, ${ }^{2}$

7 Ophthalmology, ${ }^{3}$ Physiology, ${ }^{4}$ Orthodontics, University of Pennsylvania, Philadelphia, PA 19104;

$8{ }^{5}$ Department of Preventive Dental Sciences, College of Dentistry, King Saud

9 bin Abdulaziz University for Health Sciences, Riyadh, Saudi Arabia; ${ }^{6}$ King Abdullah International

10 Medical Research Center, Riyadh, Saudi Arabia

11 Corresponding Author: Dr. Claire H. Mitchell, Department of Basic and Translational Science,

12 University of Pennsylvania, 240 S. $40^{\text {th }}$ St, Philadelphia, PA 19104-6030 Tel: 215-573-2176 FAX:

13 215-573-2324 e-mail:chm@upenn.edu 
Background: The endogenous signals leading to microglial activation represent central components of neuroinflammatory cascades. Given ATP release accompanies mechanical strain to neural tissue, and the P2X7R for ATP is expressed on microglial cells, we examined the morphological and molecular consequences of P2X7R stimulation in vivo and in vitro in detail to enhance understanding of the response.

Methods: IL-1 $\beta$ release was determined with ELISA. Expression of mRNA used qPCR. ATP release was determined with the luciferin/luciferase assay while fura-2 indicated cytoplasmic calcium. Microglial migration used Boyden chambers. Morphological changes were quantified from Iba1-

24 immunostained cells.

Results: Sholl analysis of Iba1-stained cells showed retraction of microglial ramifications one day after injection of P2X7R agonist BzATP into mouse retinae. Mean branch length also decreased,

27 while cell body size and expression of Nos2, Tnfa, Arg1, Chil3 increased. BzATP induced similar morphological changes in ex vivo tissue isolated from Cx3CR1-GFP mice, suggesting cell recruitment was unnecessary. Primary microglial cultures were developed to investigate the autonomous nature of the response. Isolated microglial cells expressed P2X7R, while increased

31 intracellular $\mathrm{Ca}^{2+}$ triggered by BzATP and blocked by antagonist A839977 confirmed functional expression. BzATP induced process retraction and cell body enlargement within minutes in

33 isolated microglial cells, and increased expression of Nos2 and Arg1. BzATP both increased

34 expression of IL-1 $\beta$, and triggered a substantial release, suggesting P2X7R both primes and 35 activates the NLRP3 inflammasome. ATP increased microglial migration, but this required 
P2Y12R, not P2X7R involvement. As ATP release often accompanies mechanical strain, responses

37 to intraocular pressure elevation were determined. Transient elevation increased ATP release and led to microglial process retraction, cell body enlargement and gene upregulation resembling

39 the responses to BzATP injection. These pressure-dependent changes to microglia were reduced

40 in $\mathrm{P} 2 \times 7 \mathrm{R}^{-/-}$mice. Critically, the loss of retinal ganglion cell neurons accompanying increased

41 pressure was correlated with microglial activation in $\mathrm{C} 57 \mathrm{BI} / 6 \mathrm{~J}$, but not $\mathrm{P} 2 \mathrm{X} 7 \mathrm{R}^{-/}$mice.

42 Conclusions: P2X7R stimulation induced morphological and molecular markers of activation in

43 retinal microglial cells in vivo and in vitro, affecting IL-1 $\beta$ release and rapid process retraction but

44 not cell migration. Parallel responses accompanied transient pressure elevation, suggesting ATP

45 release and $\mathrm{P} 2 \mathrm{X} 7 \mathrm{R}$ stimulation contribute to the microglial response to rising pressure.

\section{$46 \quad$ Key Words}

47 Microglial activation, P2X7 receptor, neuroinflammation, mechanical strain, IL-1 $\beta$, NLRP3

48 inflammasome, Sholl analysis, migration 
Introduction

Microglial cells are resident immune cells in neural tissue comprising $10-15 \%$ of neural

51 tissue[1, 2], and are the primary cells of the central nervous system that are responsible for

52 synaptic maintenance and innate immune response to injury or microbial infiltration $[2,3]$.

53 Dysregulation of microglia are implicated early events in several neuroinflammatory pathologies

$54[4-6]$.

55 Microglia are fundamentally plastic, and undergo morphologic and molecular alterations

56 when progressing from immunoquiescent, or $\mathrm{M0}$, states into "activation" in response to

57 exogenous triggers, accompanied by upregulation of microglial markers such as Iba1 [7] and

58 CX3CR1 [8, 9]. While they are considered largely beneficial in their quiescent M0 state [10],

59 stimulation leads to activation into a number of phenotypic states, depending on the nature of

60 the specific activation trigger, simplified into classical activation (M1), or alternative activation

61 (M2). Classical activation of microglia is defined by the release of proinflammatory cytokines or

62 neurotoxic effectors, such as IL-1 $\beta$ or nitric oxide [11], respectively, and exacerbate neurotoxicity

$63[12,13]$. Alternative activation has been demonstrated to promote neurogenesis $[14,15]$, axon

64 remodeling [16], or remyelination [17] after an injury. An understanding of the varied effects of

65 upstream regulators is important.

66

Changes in microglial morphology accompany activation states away from M0

67 neuroinflammation and cytokine release and have served as markers for neurodegenerative

68 diseases $[18,19]$. Immunoquiescent microglia have elongated processes and surveil their

69 immediate environment [20] and interact with synapses [21]. Microglia demonstrate a diverse

70 repertoire of morphological classifications $[18,22]$ but common morphologic alterations 
71 observed with microglial activation include enlargement of soma size and reduction of branch

72 length [23-25]. Phenotypic alterations have been associated with loss of neural populations in

73 models of epilepsy [26, 27], traumatic injury [23], and stroke [24]. In glaucoma, microglial

74 activation accompanied loss of retinal ganglion cells [28-30].

Extracellular ATP and the purinergic receptor P2X7 (P2X7R) have been identified as upstream effectors of microglial inflammation. ATP has been found in the parenchymal

77 environment from mechanical perturbation [31-36], lysosomal exocytosis [37, 38], or cell death [39]. Once released, the extracellular ATP can stimulate ionotropic P2X or metabotropic P2Y receptors to mediate a response to the a number of stimuli. P2X7 is an nonselective ionotropic receptor stimulated with high millimolar ATP concentrations [28], and that is largely expressed

81 on microglia within the central nervous system [40]. While a well-studied effect associated with

82 P2X7 stimulation is release of master proinflammatory cytokine IL-1 $\beta$ via the NOD-, LRR- and 83 pyrin domain-containing protein 3 (NLRP3) inflammasome, P2X7 receptor signaling is associated 84 with a variety of intracellular processes [41-44], the accurate understanding of the effects of 85 P2X7R stimulation on microglia morphological and molecular alterations associated with 86 activation are understudied. Previous work on morphology within the retina has implicated 87 adenosine receptor $A_{2 A}[45]$, or focused on the effects on P2X7R within microglia with elevated pressure [46-48] or in vitro stimulation [49] for extended periods of time. Herein, this study examines the morphological and molecular consequences of transient stimulation of P2X7 on 90 microglia. 
94 All procedures were performed in strict accordance with the National Research Council's "Guide

95 for the Care and Use of Laboratory Animals" and were approved by the University of Pennsylvania

96 Institutional Animal Care and Use Committee (IACUC) in protocol \#803584. All animals were

97 housed in temperature-controlled rooms on a 12:12 light:dark cycle with food and water ad

libitum. Mice (C57BI/6J wild type and P2XR7-/- B6.129P2-P2rx7 ${ }^{\mathrm{tm} 1 \mathrm{Gab} / \mathrm{J}}$ Pfizer and B6.129P2(Cg)-

99 CX3CR1 ${ }^{\text {tm1Litt/J }}$ mice were obtained from Jackson Laboratories (Bar Harbor, ME). B6.129P2(Cg)-

100

CX3CR1 ${ }^{\text {tm1Litt /J }}$ mice were bred with C57BL/6J mice for pups that were heterozygous for GFP

101

expression on the CX3CR1 promoter (CX3CR1 $\left.{ }^{+/ G F P}\right)$. Long-Evans and Sprague Dawley rats were

102 obtained from (Harlan Laboratories, Fredrick, MD).

103

104

Intravitreal injections

105 Intravitreal injections into $\mathrm{C} 57 \mathrm{BI} / 6 \mathrm{~J}$ mice as previously described [50]. Briefly, mice were

106 anesthetized under $1.5 \%$ isofluorane and injected under a dissecting microscope using a 107 micropipette attached to a microsyringe (Drummond Scientific Co., Broomall, PA, USA). The glass 108 pipette entered the superior nasal region of the sclera into the vitreous cavity approximately 0.5 $109 \mathrm{~mm}$ from the limbus. Total volume injected was $1.5 \mu \mathrm{l}$ over $30 \mathrm{~s}$. Injections consisted of Sterile 110 Balanced Saline solution (as a control) with or without $250 \mu \mathrm{M}$ Benzoylbenzoyl-ATP (BzATP, 111 \#B6396, Sigma Aldrich). The lens was carefully checked before processing the retinae and any 112 eyes showing signs of lens damage were excluded from the study. For qPCR measurements, gene 113 expression differences between saline-injected and naïve retinae from litter-controlled mates 114 were not significant. 
117 Mice were sacrificed and eyes removed. Dissected retinae were nicked to preserve orientation, 118 incubated with $0.1 \%$ Triton X-100 in SuperBlock buffer (ThermoScientific, \# 37515) for 30 minutes 119 at $25^{\circ} \mathrm{C}$ and then blocked with $10 \%$ goat serum in SuperBlock for 1 hour. Retinal whole mounts 120 or sections were incubated with Brn-3a (Santa Cruz Biotechnology, Inc. t\# sc-31984, 1:250) and 121 Iba1 (Wako Chemicals USA, Inc. \# 019-19741, 1:500) overnight or Iba1 alone for 48 hrs at $5^{\circ} \mathrm{C}$, 122 followed by incubation with secondary antibodies; donkey anti-goat Alexa 555-conjugated 123 antibody (\#A21432, Invitrogen, 1:500) or donkey anti-mouse IgG Alexa Fluor 488 conjugated 124 antibody (\#A21202 _ Invitrogen, 1:500) for $60 \mathrm{~min}$. Retinae were mounted with SlowFade Gold 125 anti-fade mounting medium (\#S36936, Molecular Probes). For cryosections used in Figure 5, 126 sections were rinsed in PBS, blocked with ( $1 \%$ Triton $\mathrm{X}-100,0.5 \% \mathrm{BSA}, 0.9 \% \mathrm{NaCl}$, and $5 \%$ donkey 127 serum [DKS; Jackson ImmunoResearch, West Grove, PA, USA] in 1\% PBS; PBS-T-BSA), quenched 128 using $0.3 \% \mathrm{H}_{2} \mathrm{O}_{2}$, then incubated with Iba1 (Wako Chemicals USA, Inc. \# 019-19741, 1:500) 129 prepared in PBS-T-BSA for overnight (sections) at $4^{\circ} \mathrm{C}$. Tissue and sections were rinsed in PBS then 130 blocked in PBS-T-BSA. Secondary antibody Alexa-Fluor 568 (\# A10042, Invitrogen, 1:250) 131 prepared in PBS-T-BSA was added and incubated for 2 hours. DAPI (4',6-diamidino-2132 phenylindole; 1:2000) was applied, then rinsed before sections were cover-slipped using 133 Fluoromount-G (SouthernBiotech, Birmingham, AL, USA). 
136 For retinal whole mounts subjected to saline or BzATP, Z-stacks were acquired from middle retina

137 areas using a Leica TCS SP8 Confocal (Leica, Wetzlar, Germany) with $0.5 \mu \mathrm{m}$ between z-planes, 138 and central region, middle and peripheral retina regions defined as $0.2,0.6$ and $1.0 \mathrm{~mm}$ from the 139 optic disk. Stacks were uploaded to FIJI [51] and processed to reduce background. Manual cell 140 counting of the Retinal Ganglion Cell (RGC) and Inner Plexiform (IPL) layers were performed. For 141 tracing or soma Iba1-intensity measurements, images were de-identified and cells were chosen 142 randomly using Randomizer.org (www.randomizer.org). For retinal cryosections, images of non143 peripheral retinal areas were acquired using a Nikon Eclipse microscope (Nikon, USA) and NIS 144 Elements Imaging software (Nikon v. 4.60). All cells of the RGC and IPL layers were utilized for 145 soma Iba1-intensity measurements. For Sholl analysis and summed branch measurements, Iba1146 positive cells were manually traced using the FIJI Simple Neurite Tracer (SNT) plugin [52]. Sholl 147 analysis was performed starting $5 \mu \mathrm{m}$ from the center of the soma and analyzed every $1 \mu \mathrm{m}$ 148 thereafter. Iba1 soma intensity was measured in the z-stack using FIJI Measure plugin within a 5 $149 \mu \mathrm{m}$ ring centered at the soma and averaged from the z-stack at the peak fluorescence $\pm 1 \mu \mathrm{m}( \pm$ 1502 z-slices) in the z-plane to account for soma depth.

\section{Quantitative PCR}

153 Retinae or isolated microglia were homogenized using $1 \mathrm{ml}$ or $500 \mu \mathrm{l}$ TRIzol reagent (\#15596018, 154 Invitrogen), respectively. RNA was purified using an RNeasy mini kit (\#79254, Qiagen, Inc.). RNA 155 concentration and purity were assayed using a Nanodrop spectrophotometer (Thermo 156 Scientific). Conversion to cDNA was performed using the High Capacity cDNA Reverse 157 Transcription Kit (\#4368814, Applied Biosystems) at $25^{\circ} \mathrm{C}$ for $10 \mathrm{~min}, 37^{\circ} \mathrm{C}$ for $120 \mathrm{~min}$ and 
158 terminated at $85^{\circ} \mathrm{C}$ for $5 \mathrm{~min}$. In most experiments, qPCR was performed with Power SYBR green 159 (\#4367659, Applied Biosystems) on the 7300 Real-Time PCR system (Applied Biosystems Corp.) 160 using standard annealing and elongation protocols. For isolated microglia subjected to BzATP, 161 Lipopolysaccharides (LPS, \#L6529, Sigma-Aldrich), or Interleukin-4 (IL-4, \#I1020, Sigma-Aldrich), 162 expression was assayed using PowerUp Sybr Green (\#A25742, Applied Biosystems) on the Quant 163 Studio 3 Real-Time PCR system (Applied Biosystems Corp.) in Fast mode, again using standard 164 annealing and elongation protocols. Data was analyzed using the delta-delta CT approach 165 without conversion to RQ values as described [53]. Primers are listed in Figure S1.

Mouse retinal whole mount isolation

CX3CR1 ${ }^{+/ G F P}$ mice were euthanized by $\mathrm{CO}_{2}$. Eyes were enucleated and placed into isotonic solution. The cornea and iris were removed by cutting in a circular path along the ora serrata with small scissors while holding the eye at the limbus with a pair of forceps. The lens and vitreous

171 humor weres removed, and the retina detached from the eyecup by cutting the optic nerve. 4

172 radial incisions were made, approximately $2 / 3$ of the distance to the optic nerve, using spring 173 scissors to create a butterfly shape. Retinae were briefly rinsed $3 x$ with isotonic solution

174 (consisting of $105 \mathrm{mM} \mathrm{NaCl}, 5 \mathrm{mM} \mathrm{KCl}, 6 \mathrm{mM}$ 4-(2-hydroxyethyl)-1-piperazineethanesulfonic 175 (HEPES) acid, $4 \mathrm{mM} \mathrm{Na}$ 4-(2-hydroxyethyl)-1-piperazineethanesulfonic acid, $5 \mathrm{mM} \mathrm{NaHCO}, 60$ $176 \mathrm{mM}$ mannitol, $5 \mathrm{mM}$ glucose, and $1.3 \mathrm{mM} \mathrm{CaCl}_{2}, \mathrm{pH} 7.4$ ) and incubated with or without $200 \mu \mathrm{M}$

177 BzATP for 2 hours at $37^{\circ} \mathrm{C}$. Retinae were then fixed with $4 \%$ PFA for 15 minutes at $25^{\circ} \mathrm{C}$ and 178 mounted using SlowFade Gold anti-fade mounting medium (\#S36936, Molecular Probes). 
Primary cell cultures

181

182
Mouse microglial cell cultures: Primary retinal microglia were isolated from mouse pups of both sexes P12-P20 using standard methods $[54,55]$. Briefly, eyes were enucleated and incubated in 3\% dispase (\#D4693, Sigma) in Hanks balanced saline solution without $\mathrm{Ca}^{2+} / \mathrm{Mg}^{2+}$. Retinae were removed and dissociated mechanically before growing on T75 flasks. Primary brain microglia were isolated along with retinal microglia for testing of microglia migration using published methods [56]. Brains were isolated, mechanically dissociated, and digested using $0.25 \%$ trypsin (\#, Sigma) with 1 M HEPES buffer solution (\#15630080, Thermo Fisher) in High Glucose Dulbecco's Modified Eagle Medium (HG-DMEM) for 30 min rocking at $37 \mathrm{C}$. Once finished, suspension was centrifuged at $500 \times \mathrm{g}$ and grown on T75 flasks with 3 brains per flask. In both cases, T75 flasks were pre-coated with Poly-L-Lysine (PLL, 0.01\%, \#OKK-3056, Peptides International) followed by Collagen IV (2 $\mu \mathrm{g} / \mathrm{ml}$, \#354233, Corning) as described [57] and grown in HG-DMEM with 10\% Fetal Bovine Serum (FBS), 1\% Penicillin/Streptomycin (Pen/Strep, \#15140122, Gibco), 1\% GlutaMAX (\#35050061, Gibco), and 1x MEM nonessential amino acids (\#M7145, Sigma-Aldrich). Once cultures became confluent, microglia were "shaken off" manually and plated in dishes coated with $0.1 \%$ Poly-L-Lysine and Collagen IV $(4 \mu \mathrm{g} / \mathrm{ml})$. Microglial growth media contained DMEM plus $5 \%$ FBS, and $10 \%$ of media previously exposed to the mixed cell culture for 5-7 days. Cells grown without this preconditioned media showed lower rates of survival. Media was changed to DMEM containing only 5\% FBS, 1\% Pen/Strep, 1\% GlutaMAX, and 1x MEM nonessential amino acids 24 hrs prior to experimentation.

Rat microglial cell cultures: Microglial cells were isolated from neonatal rat retinae using step 1 of the 2-step immunopanning protocol described previously [58]. In brief, retinae of Long Evans 
202 rat pups PD 3-7 of both genders were dissected from each eye globe and dissociated for 30 min 203 at $37^{\circ} \mathrm{C}$ in Hank's balanced salt solution (HBSS; Gibco, Inc. Invitrogen Corp., Carlsbad, CA) 204 containing $15 \mathrm{U} / \mathrm{mL}$ papain, $0.2 \mathrm{mg} / \mathrm{mL}$ DL-cysteine and 0.004\% DNase I. The retinae were 205 washed and triturated in HBSS with $1.5 \mathrm{mg} / \mathrm{mL}$ ovomucoid, $1.5 \mathrm{mg} / \mathrm{mL}$ bovine serum albumin 206 (BSA) and 0.004\% DNase I, incubated with rabbit anti-rat macrophage antibody (10 min, 1:75, 207 Accurate Chemical, Westbury, NY), centrifuged at $1000 \mathrm{rpm}$ for $10 \mathrm{~min}$, and washed. Cells were 208 re-suspended in phosphate-buffered saline (PBS) containing $0.2 \mathrm{mg} / \mathrm{mL} \mathrm{BSA}$ and $5 \mu \mathrm{g} / \mathrm{mL}$ insulin, 209 and incubated for $15 \mathrm{~min}$ in a $100 \mathrm{~mm}$ Petri-dish coated with goat anti-rabbit IgG antibody (1:400, 210 Jackson ImmunoResearch Inc, West Grove, PA). After shaking and washing to remove unattached 211 cells, microglia were detached with 0.05\% trypsin and cultured with growth medium (HG-DMEM 212 containing 10\% fetal bovine serum, 1\% Pen/Strep, 1\% GlutaMAX, and 1x MEM nonessential 213 amino acids) on 6-well plates.

214 Rat astrocyte cultures: Primary cultures were grown from grown from optic nerve heads derived 215 from Long-Evans rats as previously described [37]. In brief, rat pups of either gender were 216 sacrificed by P5, and the optic nerve head digested for 1-2 hours with $0.25 \%$ trypsin (\#25200056, 217 Sigma-Aldrich). After trituration and washing, cells were grown in DMEM/F12, 10\% FBS, 1\% 218 penicillin/streptomycin, and $25 \mathrm{ng} / \mathrm{ml}$ epidermal growth factor (\#E4127, Sigma-Aldrich) on 35 $219 \mathrm{~mm}$ culture dishes coated with PLL and grown at $37 \mathrm{C}, 5.5 \% \mathrm{CO}_{2}$. Cells were determined to contain $220>99 \%$ GFAP-positive cells (\#MABH360, Chemicon International Inc), defined as astrocytes.

222 Immunocytochemistry 
223 Isolated retinal microglial cells were mounted on $12 \mathrm{~mm}$ glass coverslips coated with PLL and 224 collagen as above. Cells were fixed in $4 \%$ paraformaldehyde for 10 min at $37^{\circ} \mathrm{C}$, washed in PBS 225 with 1\% Tween 20 (\#170-6531, Bio-Rad), permeabilized with 0.1\% Triton-X 100 for 15 min 226 (\#T8787, Sigma-Aldrich) then blocked with 20\% Superblock (\#37515, ThermoScientific) plus 10\% 227 goat or donkey serum. Primary antibodies against the following targets were used P2X7R (\#APR228 008, Alomone Labs, 1:200) then donkey anti-goat Alexa555 (\#A21432, Invitrogen, 1:500); Iba1 229 (\#AB48004, Abcam, 1:200) then donkey anti-rabbit Alexa488 (\#A21206, Invitrogen, 1:500); Iba1 230 (\#019-19741, Wako, 1:500) then goat anti-rabbit Alexa546 (\#A11035, Invitrogen, 1:500) or 231 donkey anti-rabbit Alexa555 (\#A31572, Invitrogen, 1:500); GFAP (\#MAB312 Chemicon, 1:500) 232 followed by goat anti-mouse Alexa488 (\#A11001, Invitrogen, 1:500) or donkey anti-rabbit 233 Alexa555 (\#A31572, Invitrogen, 1:500) and donkey anti-mouse Alexa488 conjugated antibody 234 (\#A11055, Invitrogen, 1:500); Synaptophysin (\#MA5-14532, Invitrogen, 1:250) followed by 235 donkey anti-goat Alexa555 (1:500). After incubation in Hoechst (\#4082S, Cell Signaling, 1 Mg/ml)

236 for 10 min, coverslips were washed and mounted using SlowFade Gold anti-fade mounting 237 medium (\#S36936, ThermoFisher). Imaging was performed using a Nikon Eclipse microscope 238 (Nikon, USA) and NIS Elements Imaging software (Nikon v. 4.60). ImageJ was used in parallel 239 processing to modify intensity, and merge pseudocolored images.

$241 \quad C a^{+2}$ imaging

242 Microglia were plated on $25 \mathrm{~mm}$ coverslips that were coated with PLL $4 \mu \mathrm{g} / \mathrm{ml}$ Collagen IV and

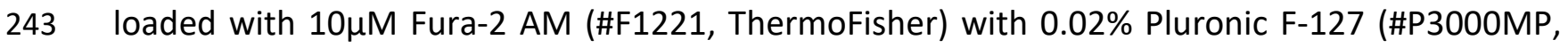
244 Thermo Fisher) for $45 \mathrm{~min}$ at $37^{\circ} \mathrm{C}$. Cells were washed, mounted in a perfusion chamber, and 
245 perfused with isotonic solution. Ratiometric measurements were performed using a 40x 246 objective on a Nikon Diaphot microscope (Nikon, USA) by alternating excitation between 340nm 247 and $380 \mathrm{~nm}$ wavelengths and quantifying emission $\geq 512 \mathrm{~nm}$ with a charge-couple device camera 248 (All Photon Technologies International, USA) as described [59]. Data were expressed as the ratio

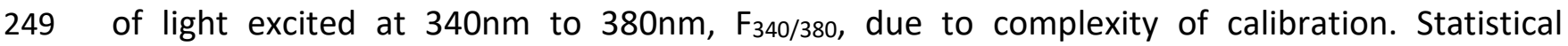
250 comparisons were made using the average of the final five measurements in each condition.

252 Time-lapse of morphological alterations

253 Retinal mouse microglia were plated as above and incubated in $\mathrm{Mg}^{2+}$-free isotonic solution with $25410 \mu \mathrm{M}$ A839977 (\#4232, Tocris) or DMSO as solvent control. Phase contrast images were taken 255 every 12 or 15s using a Keyence BZ-X700 Series All-in-One Fluorescence Microscope (Keyence 256 Corporation, Itasca IL). BzATP (\#B6396, Sigma Aldrich) was added in the presence of A839977 or 257 vehicle. Representative video was derived using "Focus tracking" function, where time-lapse 258 video is comprised of best-focused images derived from a panel of 7 images spaced $0.7 \mu \mathrm{m}$ apart 259 at each time point. FIJI [51] was used to modify intensity, with parallel processing for all time260 lapsed sequences.

\section{Microglia migration}

263 Microglia were grown to $80 \%$ confluence on a T75 flask and lifted with $0.25 \%$ trypsin, spun down 264 at $500 \times \mathrm{g}$ and resuspended in media outlined above to a concentration of 50,000 cells in $390 \mu \mathrm{l}$. 265 Cells were incubated in $1 \mu \mathrm{M}$ A839977, $10 \mu \mathrm{M}$ AR-C 69931 (\#5720, Tocris), or vehicle for $1 \mathrm{hr}$, 266 after which Hoechst nuclear dye $(1 \mu \mathrm{g} / \mathrm{ml})$ was added for 10 minutes. The cell suspension was 
267 added to the top wells of a Boyden chamber (\#AA96, Neuroprobe), separated from a solution of

$2681 \mathrm{mM}$ ATP (\#A2383, Sigma) in media by a $10 \mu \mathrm{m}$ pore filter. Cells were allowed to migrate for 3

269 hrs, after which unmigrated cells were removed from the top of the filter. Filters were washed in

270 PBS and fixed in 4\% Paraformaldehyde in PBS, washed again, then imaged using the Lumoniskan

271 Ascent fluorometer (ThermoFisher) at 340ex/527em. Values of background fluorescence were

272 subtracted and conditions were normalized to control. To validate fluorescence measurements,

273 images were acquired of labeled cells attached to the underside the pore filter and cells counted,

274 with cell numbers compared to fluorescence measurements.

275

276 Intraocular pressure elevation

277 Transient elevation of IOP: A transient controlled elevation of IOP (CEI) procedure was produced

278 in adult mice of both sexes using a modification of the approaches of Morrison [60] and Crowston

279 [61] as described [62]. In brief, mice were deeply anesthetized with $1.5 \%$ isoflurane after

280 receiving $2 \mathrm{mg} / \mathrm{kg}$ meloxicam. Proparacaine (0.5\%) and tropicamide (0.5-1\%) were administered

281 and one eye was cannulated with a 30- gauge needle attached to polyethylene tubing (PE 50,

$282 \# 427411$, Becton Dickinson, NJ) inserted into the anterior chamber, connected to a $20 \mathrm{ml}$ syringe

283 filled with sterile phosphate buffered saline (PBS). IOP was increased to $56.4 \pm 0.4 \mathrm{mmHg}$ by

284 elevating the reservoir to the appropriate height; blood flow through the retina was maintained

285 throughout to avoid acute ischemia, although some reduction in blood flow is likely. After 4 hrs,

286 IOP was returned to baseline, the needle removed and $0.5 \%$ erythromycin was applied to the

287 cornea. The contralateral eye without cannulation served as a normotensive control. Retinal

288 tissues were isolated 22-24 hrs after elevation of IOP. 

method. Ocular hypertension was mechanically induced in $2.5 \%$ isoflurane-anesthetized mice, using $2 \mu \mathrm{L}$ of magnetic microbeads (COMPEL COOH-Modified 8- $\mu$ m diameter, UMC4001; Bangs Laboratories, Fishers, IN, USA) injected into the anterior chamber of the eye using a glass-pulled micropipette connected to a manual microsyringe pump (World Precision Instruments, Sarasota, FL, USA) as described [63]. Magnetic beads were distributed along the trabecular meshwork using 295 a neodymium magnet that draws them into the iridocorneal angle, allowing microbeads to block aqueous humor outflow through the trabecular meshwork. The resulting accumulation of 297 aqueous humor causes an increase in IOP [64]. Both eyes were injected with beads to eliminate 298 the confounding factor of contralateral eye effects on glial activation [65]. Separate mice injected 299 with saline served as controls. This model proved reliable with minimum damage to ocular structures. Ten IOP measurements per eye of lightly isoflurane-anesthetized mice (2.5\%) were 301 taken and averaged; a baseline measurement was taken before bead injection, then weekly 302 measurements after bead injection for 7 weeks using the TonoLab tonometer (Colonial Medical 303 Supply Co, Londonderry, NH). The IOP integral (mm Hg-days exposure over baseline) was 304 calculated to quantify cumulative IOP elevation [63]. Fixed retinae were cryoprotected in $30 \%$ 305 sucrose and $0.02 \%$ sodium azide in $0.1 \mathrm{M}$ PBS and embedded in optimal cutting temperature 306 medium for sagittal at 10 to $15 \mu \mathrm{m}$ using a Leica cryostat. Six to ten representative slides (three307 four sections/slide) were imaged. Images were captured using a Nikon Eclipse microscope (Nikon, 308 USA). Mean intensity of Iba1 in microglia soma were analyzed using four sections per slide, and 309 ten slides per retina using Image J. Data was derived from the central regions of the retina, consistent with above methods of intensity measurements. 
312 Vitreal ATP measurement

313 ATP was determined by fast-freezing the eye as soon as IOP returned to baseline, then dissecting

314 the eye over dry ice, and collecting vitreal samples by chipping away frozen samples. This

315 prevented intracellular ATP from the cut tissue edges from seeping into the vitreous and

316 contaminating the sample [32]. ATP levels were measured using the luciferin/luciferase assay

317 (Sigma-Aldrich Inc.) as described [32].

319 Observer quantification of morphological alterations

320 Retinal whole mount images were acquired using a Nikon Eclipse microscope (Nikon, USA), and

321 images collected from the central, middle, and peripheral regions of the retina as defined above,

322 with images taken from the superior, nasal, inferior, and temporal quadrants at each distance

323 from the optic nerve. Images were de-identified and scored individually based upon morphology,

324 with smaller cell body size and elongated, thin processes receiving a score of 1 and larger body

325 size and short, thick processes receiving a score of 3 (Fig. S3A, C). Methods were validated by 326 correlating observer scoring of BzATP-exposed retinae to Iba1-intensity of the soma region (Fig.

327 S3B). There was close agreement between different observers, with the standard deviation of 328 the scores between observers being less than $15 \%$ of the mean across all regions, validating the 329 approach. 
332 For mouse experiments, isolated microglial cells were isolated and replated using the shake-off 333 method as outlined above, and subsequently primed with $1 \mu \mathrm{g} / \mathrm{ml}$ lipopolysaccharides (LPS, 334 \#L6529, Sigma-Aldrich) prior to exposure to agonist. IL-1 $\beta$ was measured using the either the 335 Mouse IL-1 beta/IL-1F2 Quantikine ELISA kit (\#MLB00C, R\&D Systems) following the 336 manufacturer's instructions, with minor alterations. Briefly, supernatants were removed and 337 spun down at $500 \times \mathrm{g}$ to remove cell debris. Samples, standards, and controls were added to 338 microplate and allowed to bind overnight at $4 \mathrm{C}$. Washes, substrate solution, and stop solution 339 were added as outlined. Optical density was measured at $450 \mathrm{~nm}$ with subtraction of $540 \mathrm{~nm}$ 340 measurements using the SpectraMax ABS (Molecular Devices). Values were converted back into 341 absolute amounts using the standard curve. Due to the high variability between experiments, 342 experimental conditions were normalized. IL-1 $\beta$ from rat microglial cells and astrocytes were 343 primed with $500 \mathrm{ng} / \mathrm{ml}$ LPS and rat Interleukin-alpha (IL-1 $\alpha, \# 500 \mathrm{RL}-005, \mathrm{R} \& \mathrm{D}$ Systems) followed 344 by exposure to agonist. IL-1 $\beta$ was measured using the Rat IL-1 beta/IL-1F2 Quantikine ELISA Kit 345 (\#RLB00, R\&D Systems) following the manufacturer's instructions.

347 Data analysis

348 Data are displayed as mean \pm standard error of the mean. Statistical analysis was performed using 349 GraphPad Prism software version 9.0.0 (Graphpad Software, Inc. San Diego Ca, USA). Normality 350 of data was tested using the Shapiro-Wilk test. Significant differences between two groups were 351 assessed by Student's t-test; paired Student's t-tests employed when making 1:1 comparisons. 352 For comparisons among three groups, one-way analysis of variance (ANOVA) with Dunnet's 353 multiple comparison's test. For comparisons among four groups, two-way ANOVA followed by 
354 Tukey's multiple comparison's test or was applied. For quantification of calcium imaging or Sholl analysis, One-way or Two-way ANOVA with Repeated measures with Sidak's test for multiple comparison's was used, respectively. Results returning $p<0.05$ were considered significant.

\section{Results}

P2X7 receptor stimulation leads to morphologic and molecular activation of microglia in vivo.

The response of microglial cells in vivo to the $\mathrm{P} 2 \mathrm{X} 7$ receptor agonist BzATP was

362 investigated to determine whether stimulation of the $\mathrm{P} 2 \mathrm{X} 7$ receptor was sufficient to evoke

363 morphologic changes. BzATP $(250 \mu \mathrm{M})$ or saline control was injected intravitreally into eyes of $364 \mathrm{C} 57 \mathrm{BI} / 6 \mathrm{~J}$ mice, and retinae removed after 24 hours. Treatment with BzATP led to elevated Iba1 365 staining and retracted microglial processes, consistent with microglial activation (Fig. 1a-d) [6,7]. 366 Microglia reside primarily in the Retinal Ganglion Cell Layer (RGCL) Inner Plexiform Layer (IPL), 367 and the Outer Plexiform Layer (OPL) of the retina, where they maintain homeostasis near 368 synapses $[66,67]$. The elevated Iba1 immunoreactivity following BzATP injection was observed 369 mainly in the RGCL and IPL (Fig. 1c, d).

371 were traced to produce binary outputs, and Sholl analysis was performed (Fig. 1e) [24]. Retinal 372 BzATP exposure led to a significant reduction in microglial process length and complexity 373 compared to saline controls (Fig. 1f). Furthermore, the cumulative length of all branches was 374 reduced (Fig 1g), representing a reduction in summed process length (Fig. S2). Iba1 intensity was 375 measured in a defined area $(5 \mu \mathrm{m})$ encircling the microglial soma in randomly selected microglia 
376 from saline- or BzATP-injected eyes (Fig. 1h, I). Exposure to BzATP led to a significant elevation of

377 Iba1 immunostaining intensity when compared to control counterparts (Fig. 1j), reflecting a 378 combination of increased soma size and Iba1 expression. Evaluation of changes to microglial 379 morphology based on Iba1 intensity and process retraction by masked observers found 380 consistent signs of activation in retinae exposed to BzATP (Fig. 1k, S3).

Microglia display a variety of molecular gene-expression states in response to insult or

382 injury; these are traditionally characterized into classical activation and alternative activation, 383 with classical activation (M1) broadly associated with a pro-inflammatory state, and alternative 384 activation (M2) promote neural repair $[11,16,18,68-70]$, although cell states are now recognized 385 as being more fluid and less binary [2, 71-73]. To evaluate the changes in gene expression 386 accompanying P2X7 receptor stimulation, qPCR was performed on retinal tissue; genes 387 associated with classical activation, Nos2 and Tnfa, and genes associated with the alternative 388 activation state, Arg1 and Chil3, were elevated in retinae 24 hours after in vivo exposure to BzATP 389 (Fig. 1l). Together, the morphological and molecular changes are consistent with microglial 390 activation in response to P2X7R stimulation.

The response of microglial cells in isolated retinal whole mounts to agonist BzATP was 392 examined to determine if resident microglia were sufficient for observed alterations in 393 morphology following P2X7 receptor stimulation. The use of an ex vivo retinal whole mount 394 restricted the response to microglial cells already present in the retina. Retinal whole mounts 395 derived from heterogeneous mice with a fluorescent tag attached to microglia/macrophage 396 receptor $\mathrm{CX} 3 \mathrm{CR} 1^{+/ \mathrm{GFP}}$ were used to track the response most effectively. Retinal whole mounts 397 were placed in a petri dish and BzATP $(200 \mu \mathrm{M})$ was added for 2 hours. Exposure to BzATP led to 
398 a considerable increase in fluorescence, with morphological changes resembling those observed 399 after BzATP injection. The increased signal was most noticeable around the optic nerve head (Fig. $4002 \mathrm{2}, \mathrm{b})$, with prominent cell bodies apparent. Exposure to BzATP also increased the signal 401 throughout the central (Fig. 2c, d) and peripheral retina, and across retinal layers (Fig. 2 e, f). This 402 ex vivo response in isolated retina suggests that microglia normally resident within the retina are 403 capable of responding to $\mathrm{P} 2 \mathrm{X} 7$ receptor stimulation, although it cannot rule out recruitment of 404 additional monocytes, which occurs in vivo. 406 cells receptor could induce effects on microglial cells directly. Dissociated retina and brain tissue were cultured in conditions that preferentially supported survival of glial cells; the microglial cells 410 growing on top of the cultures were collected using the shake-off method [55, 56, 74]. The 411 relative staining for Iba1 and astrocyte marker GFAP, and neural marker synaptophysin suggested 412 preparations contained $>95 \%$ microglial cells (Fig. 3a).

414 interleukin-4 (IL-4) to induce expression of activation state markers was determined using qPCR, 415 as these two agonists are traditionally associated with classical and alternative activation states, 416 respectively $[11,75]$. 4-hour stimulation of isolated retinal microglial cells with LPS $(10 \mathrm{ng} / \mathrm{ml})$ 417 increased expression of Nos2, Tnf, and $/ / 1 \mathrm{~b}$, while stimulation with IL-4 (10 ng/ml) increased 418 expression of markers for the alternative activation state such as Chil3 and Arg1 (Fig. 3b). These 
responses suggest cells cultured under these conditions responded as expected for microglial cells.

Immunocytochemistry staining indicated Iba1-positive cells expressed the P2X7 receptor,

422 supporting the presence of the receptor on these primary microglial cultures (Fig. 3c). Functional

423 expression of the P2X7 receptor on isolated retinal microglial cells was assessed by examining

424 levels of cytoplasmic $\mathrm{Ca}^{2+}$ with the ratiometric indicator Fura-2. A brief, 1 minute addition of

425 BzATP $(100 \mu \mathrm{M})$ raised cytoplasmic $\mathrm{Ca}^{2+}$ in the microglial cells (Fig. 3d, e); the response was rapid,

426 with most cells showing a response within $20 \mathrm{sec}$. The response was also reversible upon wash-

427 out of BzATP, and repeatable upon reapplication; these characteristics are consistent with an

428 ionotropic channel with little inactivation like the P2X7 receptor and have been observed 429 previously [76]. The P2X7R-specific inhibitor A839977 [77] significantly reduced the Ca ${ }^{2+}$ rise 430 triggered by BzATP, with the response to BzATP evident after removal of the A839977 confirming 431 this decrease was not due to Fura-2 depletion (Fig 3d, e). Together this supports the functional 432 presence of $\mathrm{P} 2 \mathrm{X} 7$ receptors on these isolated retinal microglial cells.

The effect of BzATP on microglial morphology was examined next. BzATP triggered a 434 retraction of microglial processes and a rounding of the cell body (Fig. $4 \mathrm{a}, \mathrm{S3}$ ) in greater than $75 \%$ 435 of observed cells. This response was rapid, starting less than 7 minutes after BzATP application 436 (Fig. S4). The effect of BzATP on microglial morphology was greatly reduced or inhibited in the 437 presence of inhibitor A839977, supporting action at the $\mathrm{P} 2 \mathrm{X} 7$ receptor. This suggests that 438 stimulation of the $\mathrm{P} 2 \mathrm{X} 7$ receptor was sufficient to trigger the morphological changes seen in vivo, 439 and that these changes occurred rapidly. Stimulation of the P2X7 receptor on isolated microglial 440 cells also induced changes in gene expression with parallels to those observed in vivo after P2X7 
441 receptor stimulation. Specifically, the endogenous agonist ATP (Fig. 4b), and P2X7 receptor 442 agonist BzATP (Fig. 4c) both increased expression of Nos2 and Arg1.

443 Stimulation of purinergic receptor P2Y12 has been shown to trigger microglial migration

444 up a purinergic gradient. This was tested in isolated retinal microglial cells using a 2-part Boyden 445 Chamber across a filter. Initial measurements indicated that the number of Hoechst-stained 446 microglial cells was closely reflected by total Hoechst fluorescence (Fig. 4d, e). Subsequent 447 imaging of the filter with bound microglia confirmed elevated migration by retinal microglia 448 towards an ATP concentration gradient (1 mM) (Fig. 4f). Migration levels were optimal 3 hours 449 after the addition of cells to the chamber. This migration was inhibited with exposure to P2Y12 450 inhibitor AR-C $69931(100 \mu \mathrm{M})$, but not P2X7 inhibitor A839977 (10 $\mu \mathrm{M})$ (Fig. 4f). These data lend 451 support to in vivo results of microglial-specific activation following injection of BzATP, without 452 the need for peripheral migration.

453 Role of ATP and the $P 2 X 7$ receptor in pressure-dependent microglial activation

The effect of IOP elevation on microglial cells was examined. The mechanosensitive 455 release of ATP is one of the earliest events found after pressure elevation in rat and bovine eyes, 456 and remains elevated in mouse, rat and primate models of sustained IOP elevation [32, 33, 62]. 457 To confirm short-term changes in IOP induced a rise in extracellular ATP, the transient CEI 458 procedure was used to elevate IOP for $4 \mathrm{hrs}$, and ATP concentration was determined as soon as 459 pressure returned to baseline. Given the difficulties in sampling the small extracellular spaces in 460 the retina without touching cells to trigger mechanosensitive ATP release or rupturing cells to 461 trigger cytoplasmic ATP release, levels in the posterior vitreous were determined. The fast-frozen 
462 approach was used to prevent ATP from cut edges seeming into the vitreal chamber, as described

463 previously [32]. ATP levels sampled in the vitreal humor near the inner limiting membrane were

464 significantly elevated in eyes subjected to increased IOP as compared to normotensive controls 465 (Fig. 5a).

Previous studies have indicated that inflammatory responses were greater when 467 examined one day after IOP was returned to baseline [62], thus retinae were examined 22-24 468 hours after return of IOP to baseline after this $4 \mathrm{hr}$ elevation of IOP using the CEI procedure. 469 Staining of retinal whole-mounts for Iba1 revealed a noticeable change in microglial morphology 470 in eyes exposed to elevated IOP, with larger cell bodies and shorter processes in retinal tissue 471 exposed to elevated IOP as compared to control (Fig. 5b, c). Changes in microglial morphology 472 were quantified across Central and Middle retinal regions, excluding peripheral regions for 473 divergent cell ratios (Fig. S5a, b). Analysis indicated a clear increase in morphological signs of 474 activation in microglial cells following IOP elevation (Fig. 5d). Similar morphological differences 475 were observed in the central regions of the retinae from $\mathrm{C} 57 \mathrm{BI} / 6 \mathrm{~J}$ mice subjected to sustained 476 elevation of IOP via magnetic bead blockage of aqueous humor outflow (Fig. 5e, f). Iba1 staining 477 revealed morphological retraction of processes, cell soma swelling, and increased expression of 478 Iba1 when compared to saline-administered retinae (Fig. 5g, h). Quantification of Iba1 intensity 479 in the soma area was significantly elevated with increased IOP (Fig. 5i). Furthermore, the 480 elevation of IOP utilizing this method reinforces data that were derived using transient elevation 481 of IOP.

To evaluate the changes in gene expression accompanying the increase in IOP, qPCR was 483 performed on retinal tissue; levels were examined one day after IOP elevation as previous work 
484 indicated expression changes peaked at this point [62]. As with retinal BzATP-injection, genes 485 associated with classical activation, Nos 2 and Tnfa, and genes associated with the alternative 486 activation state, Arg1 and Chil3, were elevated (Fig. 5j). Expression of Lcn2, the gene coding for 487 inflammatory marker lipocalin 2, was also increased in the model; lipocalin 2 expression is 488 increased in microglial cells exposed to inflammatory stimuli [78] and is upregulated in retinal 489 microglial cells [79], and is increased early in humans with glaucoma [80], although expression is 490 also associated with reactive astrocytes in optic neuritis [81]. Together, the morphological and 491 molecular changes are consistent with microglial activation in response to transient pressure 492 elevation.

To determine whether the $\mathrm{P} 2 \mathrm{X} 7$ receptor contributed to the microglial responses to 494 elevated IOP, the degree of morphological and molecular change was compared between P2X7R495 /- and $\mathrm{C} 57 \mathrm{BI} / 6 \mathrm{~J}$ mice. Microglial in the retinae of $\mathrm{P} 2 \mathrm{X} 7 \mathrm{R}^{-/-}$mice displayed a smaller change in 496 morphology after exposure to transient IOP elevation (Fig. 6a, b). Histological quantification 497 confirmed that changes in microglial morphology were largely absent in retina from $\mathrm{P} 2 \mathrm{X}^{\mathrm{N}} \mathrm{R}^{-/}$- mice 498 (Fig. 6c).

Further analysis was performed to better understand the reasons for the difference 500 between wild type and $\mathrm{P} 2 \mathrm{X} 7 \mathrm{R}^{-/-}$mice. Microglial cells in normotensive retina from $\mathrm{P} 2 \mathrm{X} 7 \mathrm{R}^{-/-}$mice 501 showed a small increase in morphological activation as compared to normotensive retina from 502 wild type mice (Fig. 6d). In contrast, the morphological changes after IOP elevation were 503 significantly less in retina from $\mathrm{P} 2 \mathrm{X} \mathrm{R}^{-/-}$mice (Fig. 6e). Together this implies that the lack of an 504 IOP-induced change in microglial morphology in retina from $\mathrm{P} 2 \mathrm{X} 7 \mathrm{R}^{-/-}$mice is due to both a smaller response to increased pressure itself and a moderate increase in baseline scores. 
The expression of genes associated with non-M0 microglial states increased in retina of

$507 \mathrm{P}_{2} \mathrm{X} 7 \mathrm{R}^{-/-}$mice after exposure to elevated IOP, but the rise was smaller and results were variable.

508 The expression of genes Tnfa, Arg1 and Lcn2 increased in retina of P2X7R

509 to elevated IOP, but the rise was smaller and there was no significant change in Nos2 or Chil3

510 expression (Fig. 6f). Overall, the change in expression of genes following IOP elevation was

511 reduced in retina from $\mathrm{P} 2 \mathrm{X} 7 \mathrm{R}^{\mathrm{i}-/}$ mice as compared to $\mathrm{C} 57 \mathrm{BI} / 6 \mathrm{~J}$ mice (Fig. $6 \mathrm{~g}$ ), although changes

512 in each gene were inconsistent.

514 Stimulation of the $P 2 X 7$ receptor upregulates IIIb gene expression and IL-1 $\beta$ cytokine release.

$515 \quad$ Cytokine IL-1 $\beta$ is implicated in neuroinflammation and death of neuronal populations

516 [13]. To examine the neuroinflammatory components of P2X7 receptor stimulation, cytokine

517 release from cultured mouse retinal microglia was determined. Retinal microglial cells primed

518 with LPS $(1 \mu \mathrm{g} / \mathrm{ml})$ and exposed to ATP (3 mM) (Fig. 7a) or BzATP (200 $\mu \mathrm{M})$ (Fig. 7b) secreted

519 more IL-1 $\beta$ protein than LPS alone, and this was inhibited by P2X7 receptor antagonist A839977

$520(1 \mu \mathrm{M})$. I/1b gene expression was also upregulated in cultured microglia that were challenged

521 with ATP (1 mM) for 4 hours (Fig. 7c), indicating "priming". A similar increase in //1b expression

522 was found in vivo in retinae 24 hours after transient elevation of intraocular pressure as

523 compared to normotensive controls in both $\mathrm{C} 57 \mathrm{BI} / 6 \mathrm{~J}$ mice and $\mathrm{P} 2 \mathrm{X} 7 \mathrm{R}^{-/-}$mice, although this rise

524 in IL1b expression was significantly less in P2X7 mice than in C57BI/6J mice (Fig. 7d).

To compare the relative IL-1 $\beta$ release in microglia and astrocytes, material from rat eyes

526 was used to take advantage of available primary cultures of optic nerve head astrocytes. The 
527 amount of IL-1 $\beta$ released from microglial cells was substantially greater than that released from

528 astrocytes when both were primed and exposed to $3 \mathrm{mM} \mathrm{ATP} \mathrm{(Fig.} \mathrm{7e).} \mathrm{Taken} \mathrm{together,} \mathrm{P2X7}$

529 receptor stimulation results in gene upregulation and release of IL-1ß in microglial cells.

530 Retinal ganglion cell loss, microglial activation and the $P 2 X 7$ receptor

531 The final set of experiments examined the relationship between retinal ganglion cell loss,

532 microglial activation and the P2X7 receptor. Retinal whole mounts used above were co-stained

533 for the ganglion cell transcription factor $\mathrm{Brn3a}$ and the number of cells present in each region

534 were counted in a masked fashion. In $\mathrm{C} 57 \mathrm{BI} / 6 \mathrm{~J}$ mice, IOP elevation led to a modest reduction in

535 the number of Brn3a-positive cells as compared to normotensive eyes (Fig. 8a). Little change in

536 retinal ganglion cell number was apparent when IOP was elevated in P2RX7/- mice (Fig. 8b).

537 Quantification of Brn3a-positive cells indicated cell loss accompanying elevation of IOP in

$538 \mathrm{C} 57 \mathrm{Bl} / 6 \mathrm{~J}$ mice (Fig. 8c). In contrast, no reduction in retinal ganglion cell number was found in

$539 \mathrm{P} 2 \mathrm{RX7} 7^{--}$mice (Fig. 8c). Close overlap between microglial cells and retinal ganglion cells occurs

540 throughout the retina (Fig. 8d). To determine whether the magnitude of microglial activation was

541 associated with retinal ganglion cell loss in retinae stained for both Brn3a and Iba1, the \% of

542 ganglion cell loss was plotted against the \% rise in microglial activation score for each image.

543 There was a loose but significant correlation between ganglion cell loss and microglial activation

544 in the $\mathrm{C} 57 \mathrm{Bl} / 6 \mathrm{~J}$ mice (Fig. 8e), but not in the P2RX7 ${ }^{-/-}$mice (Fig. 8f) suggesting that microglia 545 activation may negatively influence loss of RGCs.

546

547 Discussion 

receptor activation in microglial cells. Administration of $\mathrm{P} 2 \mathrm{X7}$ receptor agonist BzATP to mice retina resulted in reduction of branch length, and increase in soma size and Iba1 expression in 551 microglial cells, emblematic of microglia activation. Furthermore, retinae exposure to BzATP 552 resulted in gene expression upregulation of Nos2, Tnfa, Arg1, and Chil3, which are associated 553 with microglial activation into a mixed M1/M2 state. In vitro data demonstrated comparable 554 morphological changes following exposure to BzATP, or molecular changes after exposure to ATP 555 or BzATP, with subsequent upregulation of M1 marker Nos2 and M2 marker Arg1 observed 4 556 hours after exposure. Finally, transient elevation of intraocular pressure resulted in similar

557 reduction in process length and complexity observed in Iba1+ cells, as well as gene expression 558 changes similar to those in retinae observed with administration of BzATP. These morphological 559 and gene expression changes were significantly reduced in retinae from $\mathrm{P} 2 \times 7 \mathrm{R}^{-/-}$mice subjected 560 to transient elevation of IOP. Given the parallels in morphological and molecular changes from 561 agonist-dependent stimulation and from elevated pressure, as well as the differences observed 562 in $\mathrm{P} 2 \mathrm{X7}^{-/}$mice, these results implicate the $\mathrm{P} 2 \mathrm{X} 7$ receptor in some of the early inflammatory 563 responses to pressure in the retina.

Microglial activation as an early event in retinal degeneration.

Microglial activation has been implicated as an early event in the DBA/2J model of

567 glaucoma [6], or chronic ocular hypertension $(\mathrm{COH})$ in rats [47, 82]. Furthermore, previous work 568 in rats demonstrated microglial activation 3 days after comparatively high concentrations of 569 BzATP [47]. The work presented here demonstrated microglial activation observed after 24 hours 
570 of BzATP administration (Fig. 1) or elevation of intraocular pressure for 4 hours (Figs. 5, 6) and

571 indicated that the time scale is earlier than reported elsewhere. Our study confirms the likelihood

572 of a direct effect of microglial P2X7 receptor stimulation on morphology, given that immune cells

573 express $\mathrm{P} 2 \mathrm{X} 7$ at a higher concentration than other cell types $[40,83]$. Furthermore, rat $\mathrm{P} 2 \mathrm{X} 7$

574 reactivity to BzATP is significantly a pEC 50 of 5 versus 4 in mouse $[84,85]$, and single nucleotide

575 polymorphism differences between mouse strains altering receptor pharmacology [85, 86].

576 Finally, the discovery that $22 \times 7$ receptor stimulation can induce cell proliferation, plus the notion

577 that tumor or inflammatory microenvironments may tonically stimulate the P2X7 receptor

578 without inducing cell death places, value on understanding the effects of submaximal $P 2 X_{7}$

579 receptor stimulation [87]. Taken together, administration of a submaximal dose of BzATP

580 resulted in early activation of microglia, and points to P2X7 signaling as upstream to microglial 581 activation.

P2X7 receptor stimulation results in mixed activation state.

The data presented herein add to the growing body of evidence that the molecular response to transient $\mathrm{P} 2 \mathrm{X}_{7}$ stimulation cannot be strictly categorized to $\mathrm{M} 1$ or $\mathrm{M} 2$-like cell state.

586 In vivo administration of BzATP or elevation of IOP resulted in retinal gene upregulation of both

587 M1 markers 4-hour stimulation of the P2X7 receptor in cultured microglia with 1 mM ATP or 200 $588 \mu \mathrm{M}$ BzATP resulted in upregulation of M1 gene marker Nos2 and M2 gene marker Arg1 (Fig. 4b, 589 c), paralleling Nos2 and Tnfa and also M2 markers Arg1 and Chil3 observed with in vivo 590 administration of BzATP, or elevation of IOP (Fig. 1l; Fig. 5j). Stimulation of the P2X7 receptor had 591 been shown to lead to upregulation of M1 markers in in a variety of inflammatory cell types [41, 
$88,89]$, with stimulation often associated with the activation step of the NLRP3 inflammasome and subsequent release of IL-1 $\beta$, widely considered to be a proinflammatory (M1) cytokine [11].

594 Previous studies utilizing acute elevation of IOP in rats have focused on neurotoxic cytokine 595 release without examination of potential compensatory release of neuroprotective factors [48].

596 However, 15-minute stimulation of the P2X7 receptor has been demonstrated to elevate protein 597 expression of M2 markers Arg1 and CD163 in the SOD1-G93A mouse model of Amyotrophic 598 Lateral Sclerosis [90], correlating with a brief induction of autophagy [44]. This suggests that 599 transient stimulation of the $\mathrm{P} 2 \mathrm{X} 7$ receptor may promote a mixed activation state, consistent with 600 phenotypic state being a complex matter $[73,75,91]$. Influencing the microglia state has been 601 suggested as therapeutic for conditions of brain trauma that are accompanied with transient 602 elevated ATP $[16,68,69]$. Furthermore, localization to general retinal areas, or near to 603 degenerating RGCs may provide information correlating state of activation with effects on retinal 604 degeneration. The correlation between regions of greatest microglial activation with RGC loss in 605 the present study emphasize this elationship, but data do not allow us to distinguish between 606 microglial activation in response to dying neurons or neurons dying in response to microglial 607 activation; distinguishing between these is of key furure interest..

608 NF-kB signaling is a well-known effector in the expression of inflammatory cytokines 609 [89][91][92], and is implicated in polarization to the M1 phenotype [93, 94], which was confirmed 610 in our exposure to upstream effector LPS/TLR4 to induce an M1 phenotype (Fig. 3b). Previous 611 work has indicated that P2X7 stimulation alone can lead to NF-kB translocation to the nucleus via 612 MyD88 [62, 95]. Modulation of NF-KB has also been demonstrated to enhance microglial 
613 polarization to the M2 phenotype, with has demonstrated benefits in models of spinal cord injury

614 [96] and cerebral ischemic injury [93].

615

616

Morphological alterations with $\mathrm{P} 2 \mathrm{X} 7$ receptor stimulation.

The intracellular and extracellular mechanisms leading to microglia activation have yet to

618 be deduced. Brief P2X7R stimulation in vitro resulted in morphological changes and expression

619 of M1/M2 markers (Fig. 4). HEK293 cells exposed to brief P2X7 stimulation with $100 \mu \mathrm{M}$ BzATP

620 resulted in actin reorganization in a process dubbed "pseudoapoptosis", with demonstrable

621 membrane blebbing and mitochondrial swelling, and the process was largely dependent upon

$622 \mathrm{Ca}^{2+}$ influx and ROCK-1 signaling [97]. In the current study, in vitro microglia were exposed to 200

$623 \mu \mathrm{M}$ BzATP for ten minutes and demonstrated no signs of membrane blebbing (Fig. 4a, Sup Fig.

624 4). However, these morphological changes were absent after incubation with Calcein-AM, which

625 binds calcium, acting effectively as a chelator (data not shown). One downstream possibility was

626 demonstrated in the BV2 microglial cell line, where LPS-induced morphological changes were

627 ablated with caspase 3/7 inhibition [98]. P2X7 receptor stimulation activates caspase-3 in rat

628 cortical neurons [99] and the J774 macrophage cell line in the context of inducing apoptosis [100],

629 but the role of calcium influx in the process is not known.

630

While changes to microglia morphology and expression of markers in vitro paralleled

631 those expressed in vivo, these experiments were conducted in the absence of factors that

632 promote immunoquiescence, such as Cx3CL1/Cx3CR1, or CD200/CD200R interactions. Cx3CR1 in

633 the CNS is present largely on microglia [101, 102]. Elimination of the receptor elevated microglial

634 activation after elevation of IOP [103] and promoted inflammatory cytokine expression, 
635 increased pro-inflammatory activation, and increased phagocytosis of photoreceptors in the rd1 636 mouse model of Retinitis Pigmentosa [104]. Furthermore, Cx3CR1-deficient mononuclear 637 phagocytes expressed higher levels of $\mathrm{P} 2 \mathrm{X} 7$ receptor than their wildtype counterparts [105]. 638 Exogenous administration of the Cx3CR1 ligand Cx3CL1 (fractalkine) reduced activation and 639 phagocytosis by activated microglia [104]. Similar results were observed with CD200R blockade 640 leading to increased activation and IL-6 and Nos2 protein expression in rat spinal macrophages, 641 and to worse outcomes in a multiple sclerosis model [106]. In neuroinflammatory diseases such 642 as Alzheimer's diseases, promotion of Cx3CLR1 signaling has been demonstrated to be beneficial 643 in reducing disease progression [107]. Interestingly, Cx3CR1 expression appears to be 644 upregulated in microglia that have been activated with P2X7 receptor stimulation (Fig. 2), 645 indicating that concurrent examination of factors that promote immunoquiescence may provide 646 a fruitful direction concurrent to understanding P2X7-mediated inflammation.

P2X7-mediate microglial activation effect on RGC degeneration.

650 the elevation of ocular pressure. The correlation between activation and the loss of retinal

651 ganglion cells suggests activation can lead to neuronal death, but it is possible the relationship

652 goes the other way, and the loss of ganglion cells contributes to microglial activation [10].

653 Likewise, while it is tempting to assume that the lack of a correlation between microglial 654 activation and neuron loss in the $\mathrm{P} 2 \mathrm{X} \mathrm{R} \mathrm{R}^{-/-}$mouse reflects receptor role in microglial activation, 655 the P2X7 receptor is also expressed on retinal ganglion cells and BzATP can kill isolated ganglion 656 cells [108]. Thus the causal direction of this correlation awaits cell specific knockdown of the P2X7 
657 receptor. The levels of pressure attained in the transient IOP elevation studies are just at the 658 point where damage is observed; while this is considerably above the pressures observed in most 659 common forms of glaucoma, the presence of microglial activation in a model of sustained 660 moderate IOP suggests there is value in the model.

The morphologic and molecular changes observed in response to transient elevation of 662 IOP suggest microglial activation is certainly one of the earliest responses to IOP elevation. In the $663 \mathrm{DBA} / 2 \mathrm{~J}$ mouse model of chronic glaucoma, morphological changes to microglial cells were 664 reported at 3 months of age, long before most markers of neural damage were detected [6]. The 665 transient controlled elevation of IOP model used in this study enables precise control over the 666 timing of pressure change, making it ideal for examining the kinetics of cellular responses [60, 667 61]. Examination at earlier time points may indicate whether microglial activation precedes 668 neuron loss in vivo. However, the rapid retraction of microglial ramifications exposed to BzATP in 669 vitro suggests changes to microglial morphology occur soon after P2X7 receptor stimulation. 670 Studies using the chronic ocular hypertension model in rats support this correlation [47, 48] but 671 did not address microglia cell state or to define any spatial correlation between activation and 672 RGC loss. Related studies have focused on associated mechanisms, such as alterations to 673 purinergic receptor expression [109], or general activation of the NLRP3 inflammasome [110]. 674 However, the current study identifies a clear role for the P2X7 receptor in morphological and 675 molecular changes in retinae.

676 Microglia activation correlated spatially to loss of RGCs, and this correlation was absent 677 in retinae from $\mathrm{P} 2 \times 7 \mathrm{R}^{-/}$mice. (Fig. 8). These data suggest $\mathrm{P} 2 \mathrm{X} 7$ is responsible for a local 678 inflammatory response. This idea agrees with the high millimolar concentration of ATP required 
679 to activate the $\mathrm{P} 2 \mathrm{X} 7$ receptor $[86,111]$. Whether RGC death and the subsequent release of ATP 680 is upstream of $\mathrm{P} 2 \mathrm{X} 7$ receptor signaling, or microglial activation mediated via $\mathrm{P} 2 \mathrm{X} 7$ receptor is a 681 contributing factor, needs to be examined. Recently, work has pointed to complex intercellular 682 signaling pathway between neurons, microglia, and astrocytes leading to neuronal cell death 683 [112-114]. Interestingly, IL-18, a product of NLRP3 inflammasome activation, has been 684 demonstrated to induce the A1 astrocyte phenotype, and the inhibition of NLRP3 inflammasome 685 signaling with NLRP3-inhibitor MCC-950 has been demonstrated to reduce it [114].

687 function three days after 30 min elevation of IOP [115]. The difference between Wang et al, and 688 our current study may be reflected in the difference of time of elevated pressure, the focus on 689 RGCs rather than microglia, or the focus on use of microelectrode arrays to study RGC function, 690 which may compromise the effects of cytokines released. Even so, P2X7 receptor stimulation has 691 been demonstrated to have a number of neuroprotective effects in neuronal models $[58,116]$ 692 even though stimulation often favors cell death [108]. The use of in vivo models with prolonged 693 elevation of IOP [110] complicates the effect on RGCs, with P2X7 stimulation of microglia leading 694 to RGC death [110], yet IL-1 $\beta$ release (a major effect of P2X7 receptor stimulation [117]) has been 695 demonstrated to protect RGCs from excitotoxic damage after exposure to NMDA [118]. These 696 observations stress the need for an open mind when distinguishing between the physiologic and 697 pathophysiologic contributions of the P2X7 receptor, and stress that small differences in models, 698 such as absolute intraocular pressure levels, may influence the outcome. 
702 retinae and in isolated microglia, and release of the protein product from LPS-primed isolated 703 microglia (Fig. 7). IL-1 $\beta$ has been traditionally termed a master cytokine, and has been 704 demonstrated to contribute to neuroinflammatory diseases [13] and influence the microglia 705 inflammatory state [119]. However, IL-1ß/IL-1R signaling in microglia needs further exploration. 706 IL-1R has been shown to be minimally expressed in microglia $[118,120]$. Yet interestingly, IL-1 707 released with concurrent P2X7 pore opening promoted microglia proliferation [117] possibly via 708 crosstalk with astrocytes [118] or endothelial cells [121]. Microglia are likely sources of IL-1ß 709 release, as astrocytes do not release much IL-1ß themselves, as confirmed in Fig. 7e [62]. Specific 710 signaling needs to be determined, however. IL-1 $\beta$ released from microglia has reduced 711 excitotoxic neuron loss [118]. Concurrent release of IL-1 $\beta$ with P2X7 receptor stimulation in vitro 712 points to downstream neurotoxic factors that may contribute to neuron loss. The role of RGC loss 713 from elevated IOP was not observed in mice where IL $1 \alpha, T N F \alpha$, and $C 1 q$ were knocked out [112, 714 114], and the role of IL-1 $\beta$ as either a factor contributing to or protecting against neural toxicity, 715 and stimulating neurons directly, or altering microglia dynamics via crosstalk with other cell 716 types, needs to be elucidated. P2X7 antagonism is a promising target for several 717 neuroinflammatory diseases, but antagonism may have unintended effects of disrupting 718 neuroprotective mediators concurrent with M2-like signaling depending on the time course. Microglia/neuron crosstalk is complex and mediated by local extensions to synapses [21].

720 Reduction of microglia dendrites as an early event to transient, submaximal P2X7 stimulation 721 may contribute to reduced RGC function and toxicity via loss of local secretion of neuroprotective 
722 factors. Careful local examination of protein expression may lead to novel therapies for RGC 723 protection in diseases of elevated ATP or pressure.

\section{Conclusion}

In summary, our results support a model where $\mathrm{P} 2 \mathrm{X} 7$ receptor stimulation alone is

727 sufficient to cause microglial activation, and that this activation occurs very rapidly after receptor

728 stimulation or elevation of intraocular pressure. Furthermore, although the P2X7 receptor is

729 traditionally associated with its proinflammatory role [41], P2X7 receptor stimulation led to a 730 mixed activation state in microglial cells, suggesting the response is complex. IL-1 $1 \beta$ cell 731 upregulation was demonstrated under a number of conditions suggestive of P2X7 receptor 732 fulfilling both the priming and the activation step of NLRP3-inflammasome signaling. The effector 733 signaling of the IL-1 3 , as well as the nature of the mixed $M 1 / M 2$ activation state with any 734 associated M2 factors needs to be determined. As P2X7 receptor modulation is being targeted 735 for retinal disorders [122], this study and subsequent work can add to a deeper understanding of 736 P2X7 receptor signaling and putative beneficial effects. 
741 Abbreviations: ATP: Adenosine triphosphate; BzATP: Benzoylbenzoyl-ATP; Ctrl: Control; Cx3CR1:

742 CX3C chemokine receptor 1; ELISA: Enzyme-linked immunosorbent assay; GFAP: Glial fibrillary 743 acidic protein; Iba1: ionized calcium-binding adapter molecule 1 ; IL-1ß: Interleukin $1 \beta$; IL-4:

744 Interleukin 4; IPL: Inner plexiform layer; IOP: Intraocular pressure; LPS: Lipopolysaccharides; 745 NLRP3: NOD-, LRR- and pyrin domain-containing protein 3; P2X7R: P2X purinoceptor 7; OPL: 746 Outer plexiform layer; RGC: Retinal ganglion cell

747 Ethics approval and consent to participate: All procedures were performed in strict accordance 748 with the National Research Council's "Guide for the Care and Use of Laboratory Animals" and 749 were approved by the University of Pennsylvania Institutional Animal Care and Use Committee 750 (IACUC) in protocol \#803584.

751 Consent for publication: N/A

752 Availability of data and material: All data generated or analyzed during this study are included in 753 this published article and its supplementary information files, or is available from the 754 corresponding author on reasonable request.

755 Competing interests: The authors declare that they have no competing interests. Dr. Mitchell is 756 named in a patent describing the use of P2X7 receptor in glaucoma but there is no conflict of 757 interest. 
758 Funding: This work was supported by grants R01 EY013434 (CHM), R01 EY015537 (CHM), 759 TL1TR001880 (KC), T32EY007035 (KC) and T32NS043126 (AHJ). The funding bodies played no 760 role in the design of the study and collection, analysis, or interpretation of data and in writing 761 the manuscript. made substantial contributions to the conception and design of the work, the 762 acquisition, analysis and interpretation of data, and drafted the work.

763 Authors' contributions: KEC made substantial contributions to the conception and design of the 764 work, the acquisition, analysis and interpretation of data, and drafted the work; WL made 765 substantial contributions to the conception and design of the work, the acquisition, analysis and 766 interpretation of data, and helped substantially revise the work; AHJ made substantial 767 contributions to acquisition, analysis and interpretation of data, and helped substantially revise 768 the work; FA made substantial contributions to the acquisition, analysis and interpretation of 769 data; AC made substantial contributions to the acquisition, analysis and interpretation of data; 770 HYT made substantial contributions to the acquisition, analysis and interpretation of data; SPC 771 made substantial contributions to the acquisition and analysis of data; PS made substantial 772 contributions to the acquisition and analysis of data; NMG made substantial contributions to the 773 acquisition and interpretation of data; $\mathrm{CHM}$ made substantial contributions to the 774 conception and design of the work, analysis and interpretation of data, and drafted the work. All 775 authors have approved the submitted version and agreed both to be personally accountable for 776 the author's own contributions and to ensure that questions related to the accuracy or integrity 777 of any part of the work, are appropriately investigated, resolved, and the resolution documented 778 in the literature. 

= 12, 9 images, 3 biological replicates). I Expression of classical activation genes Nos2, Tnfa, and

798 alternative activation genes Arg1, Chil3 is elevated in retinae exposed to BzATP. Statistical 799 800

Acknowledgements: The authors would like to thank Kelly Jordan-Sciutto for use of the Keyence microscope, Chider Chen for use of the Nanodrop, and Marco Tizano for advice on the Cx3CR1 ${ }^{+/ G F P}$ mice.

\section{Figure Legends}

Figure 1. Retinal P2X7R stimulation leads to activated microglia morphology and gene expression. a, b Retinae injected with Saline or $250 \mu \mathrm{M}$ BzATP indicated that BzATP exposure results in greater Iba1 expression and different morphology. c, d Z-projections of retina wholemounts demonstrate increased Iba1 staining in the IPL and RGC layers of the retina with BzATP exposure. e Representations of image tracing and conversion to a binary image for analysis. f. Sholl analysis indicates reduced branching complexity of microglia exposed to BzATP ( $n=41,46$ cells, 3 biological replicates). $\mathrm{g}$ Summed branch length is reduced in microglia exposed to BzATP. When compared to Saline (h), Cell soma size and Iba1 Intensity are elevated in circled area of microglia from retinae exposed to BzATP (i). j Quantification of Iba1 intensity in selected area ( $n=60,55$ cells, 3 biological replicates). $\mathbf{k}$ Observer scoring of images taken from Salineexposed or BzATP-exposed retinae supports data indicating that Iba1-positive microglia are activated upon exposure to BzATP. Each dot represents the mean value of 6 trained observers ( $\mathrm{n}$ significance shown at $* p<0.05, * * p<0.01, * * * * p<0.0001$. Scale bars represent $40 \mu \mathrm{m}(\mathrm{a}), 15 \mu \mathrm{m}$ (d), $25 \mu \mathrm{m}(\mathbf{e}, \mathbf{f})$. 
Figure 2. Ex vivo retinal wholemount P2X7R stimulation activates microglia. Retinal whole mounts isolated from Cx3CR1-GFP mice revealed increased fluorescence at the optic nerve head compared to control media (a) after exposure to $200 \mu \mathrm{M}$ BzATP for 2 hours (b). This elevation in fluorescence was also seen in the Middle Nasal areas when compared to control media (c) or after exposure to BzATP (c). d, e Z-projection of Middle-Nasal retinae exposed to control media or BzATP. Scale bar represents $50 \mu \mathrm{m}$.

Figure 3. Isolated microglia express functional P2X7 receptor. a Immunocytochemistry indicating absence of GFAP or synaptohysin in primary cultures of retinal microglial cells. b qPCR results from cultured retinal microglial cells exposed for 4 hrs to DMSO (Ctrl), $10 \mathrm{ng} / \mathrm{ml}$ LPS (LPS),

812 or $10 \mathrm{ng} / \mathrm{ml} \mathrm{IL-4} \mathrm{(IL4),} \mathrm{with} \mathrm{changes} \mathrm{in} \mathrm{relative} \mathrm{expression} \mathrm{of} \mathrm{mRNA} \mathrm{for} \mathrm{Nos2,} \mathrm{Tnfa,} \mathrm{I/1b,} \mathrm{Arg1,} \mathrm{and}$ 813 YM1 were consistent with microglial cells polarization. ( $n=6-9$ samples from 2-3 biological 814 replicates). c Immunostaining indicated presence of $\mathrm{P} 2 \mathrm{X} 7$ receptor in primary retinal microglial 815 cells. $\mathbf{d}$ Representative trace from a retinal microglia cell loaded with Fura-2 showing an elevation 816 in the cytoplasmic $\mathrm{Ca}^{2+}$ levels in response to $1 \mathrm{~min}$ BzATP $(100 \mu \mathrm{M})$. The signal is displayed as the 817 ratio of light excited at $340 / 380 \mathrm{~nm}$ and emitted $>520 \mathrm{~nm}$. The response to BzATP was reduced 818 with exposure to $1 \mu \mathrm{M}$ antagonist $\mathrm{A} 839977$ (A83) but restored upon wash out. e Quantification 819 of the increase in the ratio of light excited at $340 \mathrm{~nm}$ vs. $380 \mathrm{~nm}$, em $>520 \mathrm{~nm}$ (referred to as " $\mathrm{F}$ $820340 / 380 "$ ), indicative of cytoplasmic calcium in cells loaded with Fura-2 ( $n=3-6$ cells/replicate, 3

821 biological replicates. Statistical significance shown at $* * p<0.01, * * * p<0.001, * * * * p<0.0001$. Scale 822 bar represents $20 \mu \mathrm{m}(\mathrm{a})$, and $10 \mu \mathrm{m}(\mathrm{c})$. 
Figure 4. Isolated retinal microglia respond to $\mathrm{P} 2 \mathrm{X7}$ receptor stimulation with activation and

825 retraction a Images taken before and after application of isotonic solution (Control), $250 \mu \mathrm{M}$

826 BzATP or $250 \mu \mathrm{M}$ BzATP + $10 \mu \mathrm{M}$ A839977 (A83). In cells preincubated with $10 \mu \mathrm{M}$ A839977,

827 BzATP did not alter cell size much. Similar responses were found in $>7$ experiments. $\mathbf{b}$ Elevated

828 expression of classical activation marker Nos2 and alternative activation marker Arg1 in cultured

829 retinal microglial cells exposed to $1 \mathrm{mM}$ ATP for $4 \mathrm{hrs}$ ( $\mathrm{n}=9-10$ samples, 3 biological replicates). c

830 Similar gene expression changes were observed when microglial cells were exposed to $200 \mu \mathrm{M}$

831 BzATP for $4 \mathrm{hrs}$ ( $\mathrm{n}=3$ tests, 1 biological replicate). $\mathbf{d}$ Representative images of migration 2-part

832 Boyden chamber kit filter indicated that microglia migrate towards a $1 \mathrm{mM}$ ATP gradient. e

833 Microglia were isolated from murine brain and subjected to migration. Correlation between

834 number of Hoechst-stained nuclei per well and fluorescence at 340ex/527em (Pearson's

835 correlation $r=0.9396$ with $p=0.0001)$. $f$ Microglia migration to $1 \mathrm{mM}$ ATP was inhibited with

836 preexposure to $10 \mu \mathrm{M}$ P2Y12 inhibitor AR-C 69931 (ARC) but not $1 \mu \mathrm{M}$ P2X7-inhibitor A83 (n=17-

83720 samples, 4 biological replicates). Statistical significance shown as $* p<0.05, * * p<0.01$,

$838 * * * \mathrm{p}<0.001, * * * * \mathrm{p}<0.0001$. Scale bars represent $10 \mu \mathrm{m}(\mathrm{a}), 50 \mu \mathrm{m}(\mathrm{d})$.

840 Figure 5. Elevation of IOP releases ATP and activates microglia. a Increase in ATP concentration

841 of vitreous humor $24 \mathrm{hrs}$ after elevation of IOP via the controlled elevation of IOP (CEI) procedure

842 ( $n=3$ biological replicates). b Immunohistochemical image showing staining for Iba1 (red) in the 843 central nasal quadrant in a retinal whole mount from an unstimulated $\mathrm{C} 57 \mathrm{BI} / 6 \mathrm{~J}$ mouse eye. c 844 Iba1 staining from an analogous region of an eye after elevation of IOP, and sacrificed $24 \mathrm{hrs}$ later. 
845 Retinal microglia subject to IOP elevation showed increased soma size, increased staining for 846 Iba1, and shorter, thicker projections. $\mathbf{d}$ Quantification of morphological activation of microglia 847 across central and middle regions ( $n=48,47$ images, 3 biological replicates). e Weekly IOP 848 measurements from mice injected with magnetic beads or saline control $(n=3)$. $f$ IOP integral, 849 expressed as summed $\mathrm{mmHg}$ days exposure over baseline IOP, for bead and saline-injected eyes. $850 \mathrm{~g}$ Immunohistochemical staining of Iba1 of a cryosection of the central region of saline injected 851 eye outlines elongated processes. $\mathbf{h}$ Iba1 staining of an analogous region of a retina subjected to 8527 weeks of elevation of IOP indicates microglial phenotype emblematic of activation. i 853 Quantification of a $5 \mu \mathrm{m}$ area surrounding the soma indicates significant elevation of Iba1 854 intensity per cell ( $n=4$ retinae, 3 mice). j qPCR showing increased expression of Nos2, Tnfa, Arg1, 855 and Chil3, as was Lcn2 in the retina $24 \mathrm{hrs}$ after the CEI procedure. Dots represent change in 856 expression from a single mouse, with expression normalized to the average of unpressurized 857 contralateral eyes ( $n=4-7$ mice). Scale bars represent $20 \mu \mathrm{m}$ (b) and $50 \mu \mathrm{m}$ (g). Statistical 858 significance shown as $* p<0.05, * * p<0.01, * * * * p<0.0001$

Figure 6. P2X7 receptor is implicated in microglia activation in vivo. a Iba1 staining central nasal

861 quadrant retinal whole mount of $\mathrm{P} 2 \times 7^{-/}$mouse under baseline conditions. b 862 Immunohistochemical staining of an analogous region $24 \mathrm{hrs}$ after IOP elevation in P2X7/- mice. 863 c Observer scoring of IHC images of microglial morphology across central and middle regions of $864 \mathrm{P} 2 \mathrm{X}^{-/-}$mice suggests no differences between baseline (clear) and CEI (red) ( $\mathrm{n}=48$ images, 3 mice). 865 d Scoring of baseline conditions was greater in retina from P2X7/- mice (green) than C57BI6J mice 866 (clear) ( $\mathrm{n}=48$ images, 3 mice). e $24 \mathrm{hrs}$ after elevation of IOP, microglial activation scores were 
867 greater in C57 mice than $\mathrm{P} 2 \times 7^{-/-}$mice (3 Ctrl, $3 \mathrm{P} 2 \times 7^{-/-}$mice). $\mathbf{f}$ Increase in retinal expression of 868 Arg1, TNFa, iNOS, Chil3 and Lcn2 found 24 hrs after the CEl procedure in P2RX7\% mice (n=3-6 869 mice). $\mathbf{g}$ Relative change in retinal expression of key genes after the CEI procedure in $\mathrm{C} 57 \mathrm{BI} / 6 \mathrm{~J}$ 870 mice compared to $\mathrm{P} 2 \mathrm{RX} 7^{-/-}$mice. Values represent mean $\Delta \Delta \mathrm{CT}$ levels for each gene compared to 871 unpressurized control retinae. Scale bar represents $20 \mu \mathrm{m}$. Statistical significance shown as $872 * p<0.05, * * p<0.01$

874 Figure 7. P2X7 receptor stimulation releases cytokine IL-1ß. a Mouse retinal microglial cells 875 primed with $1 \mu \mathrm{g} / \mathrm{ml}$ LPS for three hours then exposed to an additional $3 \mathrm{mM}$ ATP released a 876 significant quantity of IL-1 $\beta$ protein into the supernatant relative to LPS alone (Control). 877 Preincubation with $1 \mu \mathrm{M}$ A83 abolished release ( $\mathrm{n}=12$ samples, 4 biological replicates). b Similar 878 pattern of IL-1 $\beta$ release was measured in primed microglial cells with $1 \mathrm{hr}$ exposure to $200 \mu \mathrm{M}$ 879 BzATP ( $\mathrm{n}=9$ samples, 3 biological replicates). c Gene expression of $/ / 1 b$ was elevated in cultured 880 mouse retinal microglia after $4 \mathrm{hr}$ exposure to $1 \mathrm{mM}$ ATP. d Gene expression of $/ / 1 \mathrm{~b}$ was 881 upregulated in $\mathrm{C} 57 \mathrm{~B} 67$ and $\mathrm{P} 2 \times 7^{-/}$retinae after elevated $\mathrm{IOP}$, but that upregulation was

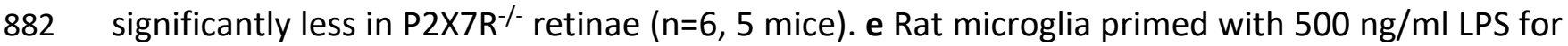
8833 hours followed by exposure to an additional $3 \mathrm{mM}$ ATP released significantly more IL-1 $\beta$ than 884 cultured rat astrocytes primed with LPS and $5 \mathrm{ng} / \mathrm{ml} \mathrm{IL-1} \alpha$, followed by similar exposure to ATP 885 ( $n=3$ samples from cultures obtained from multiple rats combined ). Statistical significance shown 886 as $* p<0.05, * * * * p<0.0001$ 

hrs after IOP elevation following IOP elevation to control C57BI/6J mice. b Decrease in Brn3a 891 staining was not observed in retinae from $\mathrm{P} 2 \times 7^{-1-}$ after IOP elevation compared to control. c 892 Fewer Brn3a-labeled RGCs were counted in retinae from C57BI/6J eyes exposed to elevated IOP 893 (red) compared to normotensive controls (clear, left). RGC numbers in control (clear, right) and 894 elevated IOP (green) in P2X7\% mice were unchanged, demonstrating that there is no pressure895 dependent loss of RGCs in the $\mathrm{P} 2 \times 7^{-/-}$mice. More Brn3a cells were quantified from $\mathrm{P} 2 \times 7^{-/}$eyes 896 subjected to elevated IOP (green) compared to C57 eyes (red) ( $n=42-46$ images, 3 mice). d Retinal 897 whole mount from a C57BI/6J mouse showing the spatial relationship between RGCs stained with 898 Brn3a (red) and Iba1 stained microglial (green); images show staining across the central region 899 with the optic nerve head (left) the middle region (center) and peripheral region (right) of the 900 optic disk are shown. e Correlation between the loss of RGCs and rise in microglial activation 901 accompanying IOP elevation. (Pearson's correlation with $p=0.038 ; n=7$ sections from central and 902 middle regions of 3 control and contralateral CEI retina). $f$ No such correlation between RGC loss 903 and microglial activation exists in regions from $\mathrm{P} 2 \times 7^{-1}$ mice. Statistical significance show as $904 * p<0.05, * * * * p<0.0001$ 905 Supplementary Figures

908 Supplementary Figure S1. List of qPCR primers. 
910 Supplementary Figure S2. a Microglial cell tracing length was quantified and total branch length

911 was normalized to the average summed branch length within each mouse. Total summed branch

912 length was reduced by approximately $10 \%$ (Mean saline $=0.9941$, mean BzATP $=0.8930$ ).

$913 * p<0.05$

914

915 Supplementary Figure S3. a Images derived from IBA1-immunostained retinal wholemounts that

916 were evaluated for morphologic or molecular markers of activation and receiving a score of 1,2 ,

917 or 3 . Scale bar represents $50 \mu \mathrm{m}$. b Significant correlation between observer scoring and 918 microglial IBA1-soma intensity was found. Each dot represents the mean value among 6 masked, 919 trained observers ( $\mathrm{n}=21$ images, 6 retinae).

920

921 Supplementary Figure S4. Videos demonstrating microglial retraction with exposure to BzATP.

92215 minute videos were recorded at 15 frames per section, with experimental solution added at $t$

$923=3 \mathrm{~min}$. a Addition of fresh $\mathrm{Mg}^{2+}$-free solution added at 3 minutes led to little or no morphological

924 changes. b Addition of $250 \mu \mathrm{M}$ BzATP at 3 minutes resulted in rapid retraction of microglial 925 extensions and rounding of cells. $\mathrm{c}$ with preexposure to $10 \mu \mathrm{M}$ A839977, the addition of $10 \mu \mathrm{M}$ $926 \mathrm{~A} 839977+250 \mu \mathrm{M}$ BzATP at 3 minutes revealed little reduction in microglia processes.

928 Supplementary Figure S5. a RGCs and b microglia cell numbers were counted per image and 929 averaged within superior inferior, nasal, or temporal regions. There was a significant difference 930 in distribution of RGCs in peripheral retinal areas, where as RGC populations in the central and 
931 middle areas demonstrated homogeneity ( $n=12$ areas, 3 mice, 2-Way ANOVA with Repeated

932 Measures). ${ }^{* *} \mathrm{p}<0.01, * * * \mathrm{p}<0.001$. 
934 1. Lawson U PV, Dri P, Gordon S: Heterogeneity in the distribution and morphology of microglia in the normal adult mouse brain. Neuroscience 1990, 39:151-170.

2. Colonna M BO: Microglia Function in the Central Nervous System During Health and Neurodegeneration. Annu Rev Immunol 2017, 35:441-468.

3. Salter MW, Stevens B: Microglia emerge as central players in brain disease. Nat Med

4. Butovsky O, Jedrychowski MP, Cialic R, Krasemann S, Murugaiyan G, Fanek Z, Greco DJ, Wu PM, Doykan CE, Kiner O, et al: Targeting miR-155 restores abnormal microglia and attenuates disease in SOD1 mice. Ann Neurol 2015, 77:75-99.

5. Mathys H, Adaikkan C, Gao F, Young JZ, Manet E, Hemberg M, De Jager PL, Ransohoff RM, Regev A, Tsai LH: Temporal Tracking of Microglia Activation in Neurodegeneration at 945 Single-Cell Resolution. Cell Rep 2017, 21:366-380.

6. Bosco A, Steele MR, Vetter ML: Early microglia activation in a mouse model of chronic glaucoma. J Comp Neurol 2011, 519:599-620.

$9487 . \quad$ Ito D TK, Suzuki S, Dembo T, Fukuuchi Y: Enhanced expression of Iba1, ionized calciumbinding adapter molecule 1, after transient focal cerebral ischemia in rat brain. Stroke

951 8. Gonzalez-Prieto M, Gutierrez IL, Garcia-Bueno B, Caso JR, Leza JC, Ortega-Hernandez A, 952 Gomez-Garre D, Madrigal JLM: Microglial CX3CR1 production increases in Alzheimer's disease and is regulated by noradrenaline. Glia 2021, 69:73-90. 
954 9. Chen S LD, Streit WJ, Harrison JK: TGF-beta1 upregulates CX3CR1 expression and inhibits fractalkine-stimulated signaling in rat microglia. J Neuroimmunol 2002, 133:46-55.

956 10. Szepesi Z, Manouchehrian O, Bachiller S, Deierborg T: Bidirectional Microglia-Neuron Communication in Health and Disease. Front Cell Neurosci 2018, 12:323.

11. Chhor V, Le Charpentier T, Lebon S, Ore MV, Celador IL, Josserand J, Degos V, Jacotot E, Hagberg H, Savman K, et al: Characterization of phenotype markers and neuronotoxic potential of polarised primary microglia in vitro. Brain Behav Immun 2013, 32:70-85.

12. Guzman-Martinez L, Maccioni RB, Andrade V, Navarrete LP, Pastor MG, Ramos-Escobar $\mathrm{N}$ : Neuroinflammation as a Common Feature of Neurodegenerative Disorders. Front Pharmacol 2019, 10:1008.

13. Wooff Y, Man SM, Aggio-Bruce R, Natoli R, Fernando N: IL-1 Family Members Mediate Immunol 2019, 10:1618.

967

14. Liu X, Liu J, Zhao S, Zhang H, Cai W, Cai M, Ji X, Leak RK, Gao Y, Chen J, Hu X: Interleukin4 Is Essential for Microglia/Macrophage M2 Polarization and Long-Term Recovery After Cerebral Ischemia. Stroke 2016, 47:498-504.

15. Jin Q, Cheng J, Liu Y, Wu J, Wang X, Wei S, Zhou X, Qin Z, Jia J, Zhen X: Improvement of functional recovery by chronic metformin treatment is associated with enhanced alternative activation of microglia/macrophages and increased angiogenesis and neurogenesis following experimental stroke. Brain Behav Immun 2014, 40:131-142. 
974 16. Kobashi S, Terashima T, Katagi M, Nakae Y, Okano J, Suzuki Y, Urushitani M, Kojima H:

975

976

977

978

979

980

981

982

983

984

985

986

987

988

989

990

991

992

993

Transplantation of M2-Deviated Microglia Promotes Recovery of Motor Function after Spinal Cord Injury in Mice. Mol Ther 2020, 28:254-265.

17. Galloway DA, Blandford SN, Berry T, Williams JB, Stefanelli M, Ploughman M, Moore CS: miR-223 promotes regenerative myeloid cell phenotype and function in the demyelinated central nervous system. Glia 2019, 67:857-869.

18. Boche D, Perry VH, Nicoll JA: Review: activation patterns of microglia and their identification in the human brain. Neuropathol Appl Neurobiol 2013, 39:3-18.

19. Butovsky O, Weiner HL: Microglial signatures and their role in health and disease. Nat Rev Neurosci 2018, 19:622-635.

20. Nimmerjahn A, Kirchhoff, F. \& Helmchen, F: Resting microglial cells are highly dynamic surveillants of brain parenchyma in vivo. Science 2005, 308:1314-1318.

21. Marinelli S, Basilico B, Marrone MC, Ragozzino D: Microglia-neuron crosstalk: Signaling mechanism and control of synaptic transmission. Semin Cell Dev Biol 2019, 94:138-151.

22. Olah M BK, Vinet J, Boddeke HWGM: Microglia Phenotype Diversity. Cns Neurological Disord - Drug Targets 2011, 10:108-118.

23. Morrison H, Young K, Qureshi M, Rowe RK, Lifshitz J: Quantitative microglia analyses reveal diverse morphologic responses in the rat cortex after diffuse brain injury. Sci Rep 2017, 7:13211.

24. Morrison HW FJ: A quantitative spatiotemporal analysis of microglia morphology during ischemic stroke and reperfusion. J Neuroinflammation 2013, 10:4. 
995 25. Davis BM, Salinas-Navarro M, Cordeiro MF, Moons L, De Groef L: Characterizing microglia activation: a spatial statistics approach to maximize information extraction. Sci Rep 2017, 7:1576.

998 26. Wyatt-Johnson SK, Herr SA, Brewster AL: Status Epilepticus Triggers Time-Dependent 999 Alterations in Microglia Abundance and Morphological Phenotypes in the Hippocampus. Front Neurol 2017, 8:700.

27. Avignone E, Lepleux M, Angibaud J, Nagerl UV: Altered morphological dynamics of activated microglia after induction of status epilepticus. J Neuroinflammation 2015, 12:202.

28. Bosco A, Romero CO, Breen KT, Chagovetz AA, Steele MR, Ambati BK, Vetter ML: Neurodegeneration severity can be predicted from early microglia alterations monitored in vivo in a mouse model of chronic glaucoma. Dis Model Mech 2015, 8:443455.

29. Beynon SB, Walker FR: Microglial activation in the injured and healthy brain: what are we really talking about? Practical and theoretical issues associated with the measurement of changes in microglial morphology. Neuroscience 2012, 225:162-171.

30. Yuan L NA: Activated microglia in the human glaucomatous optic nerve head. J Neurosci Res 2001, 64:523-532.

1013 31. Li A, Zhang X, Zheng D, Ge J, Laties AM, Mitchell CH: Sustained elevation of extracellular ATP in aqueous humor from humans with primary chronic angle-closure glaucoma. Exp Eye Res 2011, 93:528-533 
1016 32. Lu W, Hu H, Sevigny J, Gabelt BT, Kaufman PL, Johnson EC, Morrison JC, Zode GS, Sheffield 1017 VC, Zhang X, et al: Rat, mouse, and primate models of chronic glaucoma show sustained elevation of extracellular ATP and altered purinergic signaling in the posterior eye. Invest Ophthalmol Vis Sci 2015, 56:3075-3083.

33. Reigada D, Lu W, Zhang M, Mitchell CH: Elevated pressure triggers a physiological release of ATP from the retina: Possible role for pannexin hemichannels. Neuroscience 2008, 157:396-404

34. Sadananda P, Shang F, Liu L, Mansfield KJ, Burcher E: Release of ATP from rat urinary bladder mucosa: role of acid, vanilloids and stretch. Br J Pharmacol 2009, 158:16551662.

35. Takahara N, Ito S, Furuya K, Naruse K, Aso H, Kondo M, Sokabe M, Hasegawa Y: Real-time imaging of ATP release induced by mechanical stretch in human airway smooth muscle cells. Am J Respir Cell Mol Biol 2014, 51:772-782.

36. Wei L, Mousawi F, Li D, Roger S, Li J, Yang X, Jiang LH: Adenosine Triphosphate Release and P2 Receptor Signaling in Piezo1 Channel-Dependent Mechanoregulation. Front Pharmacol 2019, 10:1304.

37. Beckel JM, Gomez NM, Lu W, Campagno KE, Nabet B, Albalawi F, Lim JC, Boesze-Battaglia $\mathrm{K}$, Mitchell $\mathrm{CH}$ : Stimulation of TLR3 triggers release of lysosomal ATP in astrocytes and epithelial cells that requires TRPML1 channels. Sci Rep 2018, 8:5726. .

1035 38. Imura Y, Morizawa Y, Komatsu R, Shibata K, Shinozaki Y, Kasai H, Moriishi K, Moriyama Y, Koizumi S: Microglia release ATP by exocytosis. Glia 2013, 61:1320-1330. 
1037 39. Coddou C, Yan Z, Obsil T, Huidobro-Toro JP, Stojilkovic SS: Activation and regulation of purinergic P2X receptor channels. Pharmacol Rev 2011, 63:641-683.

1039

1040

1041

1042

1043

1044

1045

1046

1047

1048

1049

1050

1051

1052

1053

1054

1055

1056

1057

40. Kaczmarek-Hajek K, Zhang J, Kopp R, Grosche A, Rissiek B, Saul A, Bruzzone S, Engel T, Jooss T, Krautloher A, et al: Re-evaluation of neuronal P2X7 expression using novel mouse models and a P2X7-specific nanobody. Elife 2018, 7.

41. Adinolfi E, Giuliani AL, De Marchi E, Pegoraro A, Orioli E, Di Virgilio F: The P2X7 receptor: A main player in inflammation. Biochem Pharmacol 2018, 151:234-244.

42. Kopp R, Krautloher A, Ramirez-Fernandez A, Nicke A: P2X7 Interactions and Signaling Making Head or Tail of It. Front Mol Neurosci 2019, 12:183.

43. Orioli E, De Marchi E, Giuliani AL, Adinolfi E: P2X7 Receptor Orchestrates Multiple Signalling Pathways Triggering Inflammation, Autophagy and Metabolic/Trophic Responses. Curr Med Chem 2017, 24:2261-2275.

44. Campagno KE, Mitchell $\mathrm{CH}$ : The P2X7 Receptor in Microglial Cells Modulates the Endolysosomal Axis, Autophagy, and Phagocytosis. Frontiers in Cellular Neuroscience 2021, 15.

45. Aires ID, Boia R, Rodrigues-Neves AC, Madeira MH, Marques C, Ambrosio AF, Santiago AR: Blockade of microglial adenosine A2A receptor suppresses elevated pressure-induced inflammation, oxidative stress, and cell death in retinal cells. Glia 2019, 67:896-914.

46. Mitchell $\mathrm{CH}, \mathrm{Lu}$ W, Hu H, Zhang X, Reigada D, Zhang M: The P2X(7) receptor in retinal ganglion cells: A neuronal model of pressure-induced damage and protection by a shifting purinergic balance. Purinergic Signal 2009, 5:241-249 
1058 47. Dong L, Hu Y, Zhou L, Cheng X: P2X7 receptor antagonist protects retinal ganglion cells by inhibiting microglial activation in a rat chronic ocular hypertension model. $\mathrm{Mol}$ Med $\operatorname{Rep} 2018,17: 2289-2296$.

48. Sugiyama T, Lee SY, Horie T, Oku H, Takai S, Tanioka H, Kuriki Y, Kojima S, Ikeda T: P2X7 receptor activation may be involved in neuronal loss in the retinal ganglion cell layer after acute elevation of intraocular pressure in rats. Molecular Vision 2013, 19:20802091.

49. He Y, Taylor N, Fourgeaud L, Bhattacharya A: The role of microglial P2X7: modulation of cell death and cytokine release. J Neuroinflammation 2017, 14:135.

50. Hu H, Lu W, Zhang M, Zhang X, Argall AJ, Patel S, Lee GE, Kim YC, Jacobson KA, Laties AM, Mitchell $\mathrm{CH}$ : Stimulation of the $\mathbf{P} 2 \times 7$ receptor kills rat retinal ganglion cells in vivo. Exp Eye Res 2010, 91:425-432

51. Schindelin J, Arganda-Carreras I, Frise E, Kaynig V, Longair M, Pietzsch T, Preibisch S, Rueden C, Saalfeld S, Schmid B, et al: Fiji: an open-source platform for biological-image

52. Longair MH, Baker DA, Armstrong JD: Simple Neurite Tracer: open source software for analysis. Nat Methods 2012, 9:676-682.

1076 53. Lu W, Albalawi F, Beckel JM, Lim JC, Laties AM, Mitchell CH: The P2X7 receptor links mechanical strain to cytokine IL-6 up-regulation and release in neurons and astrocytes.

1079 54. Roque RS CR: Isolation and culture of retinal microglia. Curr Eye Res 1993, 12:285-290. 
1080 55. Ma W, Zhao L, Fontainhas AM, Fariss RN, Wong WT: Microglia in the mouse retina alter the structure and function of retinal pigmented epithelial cells: a potential cellular interaction relevant to AMD. PLoS One 2009, 4:e7945.

56. Lian H, Roy E, Zheng H: Protocol for Primary Microglial Culture Preparation. Bio Protoc 2016, 6.

57. Collins HY, Bohlen CJ: Isolation and Culture of Rodent Microglia to Promote a Dynamic Ramified Morphology in Serum-free Medium. J Vis Exp 2018.

58. Lim JC, Lu W, Beckel JM, Mitchell CH: Neuronal release of cytokine IL-3 triggered by mechanosensitive autostimulation of the $\mathrm{P} 2 \mathrm{X7}$ receptor Is neuroprotective. Front Cell Neurosci 2016, 10:270.

59. Gómez NM, Lu W, Lim J, Kiselyov K, Grishchuk Y, Slaugenhaupt S, Pfeffer B, Fliesler SJ, CH. M: Robust lysosomal calcium signaling through channel TRPML1 is impaired by lipofuscin accumulation Faseb J 2018, 32:782-794

60. Tehrani S, Davis L, Cepurna WO, Choe TE, Lozano DC, Monfared A, Cooper L, Cheng J,

61. Crowston JG, Kong YX, Trounce IA, Dang TM, Fahy ET, Bui BV, Morrison JC, Chrysostomou recovery in the mouse. Exp Eye Res 2015, 141:3-8. 
62. Albalawi F, Lu W, Beckel JM, Lim JC, McCaughey SA, Mitchell CH: The P2X7 Receptor Primes IL-1beta and the NLRP3 Inflammasome in Astrocytes Exposed to Mechanical Strain. Front Cell Neurosci 2017, 11:227.

63. Jassim AH, Inman DM: Evidence of Hypoxic Glial Cells in a Model of Ocular Hypertension. Invest Ophthalmol Vis Sci 2019, 60:1-15.

64. Samsel PA, Kisiswa L, Erichsen JT, Cross SD, Morgan JE: A novel method for the induction of experimental glaucoma using magnetic microspheres. Invest Ophthalmol Vis Sci 2011, 52:1671-1675.

65. Rojas B GB, Ramírez Al, Salazar JJ, de Hoz R, Valiente-Soriano FJ, Avilés-Trigueros M, Villegas-Perez MP, Vidal-Sanz M, Triviño A, Ramírez JM: Microglia in mouse retina contralateral to experimental glaucoma exhibit multiple signs of activation in all retinal layers. J Neuroinflammation 2014, 11.

66. Silverman SM WW: Microglia in the Retina: Roles in Development, Maturity, and Disease. Annu Rev Vis Sci 2018, 4:45-77.

67. O'Koren EG, Yu C, Klingeborn M, Wong AYW, Prigge CL, Mathew R, Kalnitsky J, Msallam RA, Silvin A, Kay JN, et al: Microglial Function Is Distinct in Different Anatomical Locations during Retinal Homeostasis and Degeneration. Immunity 2019, 50:723-737 e727.

68. Akhmetzyanova E, Kletenkov K, Mukhamedshina Y, Rizvanov A: Different Approaches to Modulation of Microglia Phenotypes After Spinal Cord Injury. Front Syst Neurosci 2019, 13:37.

69. Hu X, Leak RK, Shi Y, Suenaga J, Gao Y, Zheng P, Chen J: Microglial and macrophage polarization-new prospects for brain repair. Nat Rev Neurol 2015, 11:56-64. 
1122 70. Liu X, Wen S, Yan F, Liu K, Liu L, Wang L, Zhao S, Ji X: Salidroside provides neuroprotection 1123 by modulating microglial polarization after cerebral ischemia. J Neuroinflammation $1124 \quad 2018,15: 39$.

1125 71. Wes PD, Holtman IR, Boddeke EW, Moller T, Eggen BJ: Next generation transcriptomics 1126 and genomics elucidate biological complexity of microglia in health and disease. Glia $1127 \quad 2016,64: 197-213$.

1128 72. Cherry JD, Olschowka JA, O'Banion MK: Arginase 1+ microglia reduce Abeta plaque 1129 deposition during IL-1beta-dependent neuroinflammation. J Neuroinflammation 2015, $1130 \quad 12: 203$

1131 73. Ransohoff RM: A polarizing question: do M1 and M2 microglia exist? Nat Neurosci 2016, 19:987-991.

1133 74. Bronstein R, Torres L, Nissen JC, Tsirka SE: Culturing microglia from the neonatal and 1134 adult central nervous system. J Vis Exp 2013:50647.

1135 75. Lively S, Schlichter LC: Microglia Responses to Pro-inflammatory Stimuli (LPS, 1136 IFNgamma+TNFalpha) and Reprogramming by Resolving Cytokines (IL-4, IL-10). Front $1137 \quad$ Cell Neurosci 2018, 12:215.

1138 76. Guha S, Baltazar GC, Coffey EE, Tu L-A, Lim JC, Beckel JM, Eysteinsson T, Lu W, O’Brien1139 Jenkins A, Patel S, et al: Lysosomal alkalinization, lipid oxidation, impaired autophagy 1140 and reduced phagosome clearance triggered by P2X7 receptor activation in retinal 1141 pigmented epithelial cells Faseb J 2013, 27 4500-4509.

1142 77. Honore P, Donnelly-Roberts D, Namovic M, Zhong C, Wade C, Chandran P, Zhu C, Carroll W, Perez-Medrano A, Iwakura Y, Jarvis MF: The antihyperalgesic activity of a selective 

Res 2009, 204:77-81.

78. Lee S, Lee J, Kim S, Park JY, Lee WH, Mori K, Kim SH, Kim IK, Suk K: A dual role of lipocalin 2 in the apoptosis and deramification of activated microglia. J Immunol 2007, 179:32313241.

79. Parmar T, Parmar VM, Perusek L, Georges A, Takahashi M, Crabb JW, Maeda A: Lipocalin 2 Plays an Important Role in Regulating Inflammation in Retinal Degeneration. J Immunol 2018, 200:3128-3141.

1152 80. Feng J, Xu J: Identification of pathogenic genes and transcription factors in glaucoma. Mol Med Rep 2019, 20:216-224.

1154 81. Chun BY, Kim JH, Nam Y, Huh MI, Han S, Suk K: Pathological Involvement of AstrocyteDerived Lipocalin-2 in the Demyelinating Optic Neuritis. Invest Ophthalmol Vis Sci 2015, 56:3691-3698.

1157 82. Naskar R WM, Thanos S: Detection of early neuron degeneration and accompanying

84. Donnelly-Roberts DL, Namovic MT, Han P, Jarvis MF: Mammalian P2X7 receptor pharmacology: comparison of recombinant mouse, rat and human P2X7 receptors. British journal of pharmacology 2009, 157:1203-1214. 
1165 85. Young MT, Pelegrin P, Surprenant A: Amino acid residues in the P2X7 receptor that mediate differential sensitivity to ATP and BzATP. Mol Pharmacol 2007, 71:92-100.

1167 86. Donnelly-Roberts DL, Namovic MT, Han P, Jarvis MF: Mammalian P2X7 receptor

87. Di Virgilio F: P2X7 is a cytotoxic receptor....maybe not: implications for cancer. Purinergic Signal 2020.

1172 88. Burnstock G, Knight GE: The potential of P2X7 receptors as a therapeutic target, including inflammation and tumour progression. Purinergic Signal 2018, 14:1-18.

89. Sperlagh B, Illes P: P2X7 receptor: an emerging target in central nervous system

90. Fabbrizio P, Amadio S, Apolloni S, Volonte C: P2X7 Receptor Activation Modulates Autophagy in SOD1-G93A Mouse Microglia. Front Cell Neurosci 2017, 11:249.

1178 91. Morganti JM, Riparip LK, Rosi S: Call Off the Dog(ma): M1/M2 Polarization Is Concurrent following Traumatic Brain Injury. PLoS One 2016, 11:e0148001.

1180 92. Bryant CE SD, Gangloff M, Gay NJ: The molecular basis of the host response to lipopolysaccharide. Nat Rev Microbiol 2010, 8:8-14.

1182 93. Zhao R, Ying M, Gu S, Yin W, Li Y, Yuan H, Fang S, Li M: Cysteinyl Leukotriene Receptor 2 is Involved in Inflammation and Neuronal Damage by Mediating Microglia M1/M2 Polarization through NF-kappaB Pathway. Neuroscience 2019, 422:99-118.

1185 94. Zhao Q, Wu X, Yan S, Xie X, Fan Y, Zhang J, Peng C, You Z: The antidepressant-like effects of pioglitazone in a chronic mild stress mouse model are associated with PPARgamma- 
mediated alteration of microglial activation phenotypes. J Neuroinflammation 2016, 13:259.

95. Liu Y, Xiao Y, Li Z: P2X7 receptor positively regulates MyD88-dependent NF-kappaB activation. Cytokine 2011, 55:229-236.

1191 96. Chen S, Ye J, Chen X, Shi J, Wu W, Lin W, Lin W, Li Y, Fu H, Li S: Valproic acid attenuates traumatic spinal cord injury-induced inflammation via STAT1 and NF-kappaB pathway dependent of HDAC3. J Neuroinflammation 2018, 15:150.

97. Mackenzie AB, Young MT, Adinolfi E, Surprenant A: Pseudoapoptosis induced by brief activation of ATP-gated P2X7 receptors. J Biol Chem 2005, 280:33968-33976.

1196 98. Burguillos MA, Deierborg T, Kavanagh E, Persson A, Hajji N, Garcia-Quintanilla A, Cano J,

99. Kong Q, Wang M, Liao Z, Camden JM, Yu S, Simonyi A, Sun GY, Gonzalez FA, Erb L, Seye

100. Bidula S, Dhuna K, Helliwell R, Stokes L: Positive allosteric modulation of P2X7 promotes apoptotic cell death over lytic cell death responses in macrophages. Cell Death Dis 2019,

1205 101. Paolicelli RC, Bisht K, Tremblay ME: Fractalkine regulation of microglial physiology and 1206 consequences on the brain and behavior. Front Cell Neurosci 2014, 8:129. 
1207 102. Jung S AJ, Graemmel P, Sunshine MJ, Kreutzberg GW, Sher A, Littman DR: Analysis of 1208 fractalkine receptor CX(3)CR1 function by targeted deletion and green fluorescent 1209 protein reporter gene insertion. Mol Cell Biol 2000, 20:4106-4114.

1210 103. Wang K, Peng B, Lin B: Fractalkine receptor regulates microglial neurotoxicity in an 1211 experimental mouse glaucoma model. Glia 2014, 62:1943-1954.

1212 104. Zabel MK, Zhao L, Zhang Y, Gonzalez SR, Ma W, Wang X, Fariss RN, Wong WT: Microglial 1213 phagocytosis and activation underlying photoreceptor degeneration is regulated by CX3CL1-CX3CR1 signaling in a mouse model of retinitis pigmentosa. Glia 2016, 64:14791491.

1216

105. Hu SJ, Calippe B, Lavalette S, Roubeix C, Montassar F, Housset M, Levy O, Delarasse C, Paques M, Sahel JA, et al: Upregulation of P2RX7 in Cx3cr1-Deficient Mononuclear Phagocytes Leads to Increased Interleukin-1beta Secretion and Photoreceptor Neurodegeneration. J Neurosci 2015, 35:6987-6996.

106. Meuth SG, Simon OJ, Grimm A, Melzer N, Herrmann AM, Spitzer P, Landgraf P, Wiendl H: CNS inflammation and neuronal degeneration is aggravated by impaired CD200CD200R-mediated macrophage silencing. J Neuroimmunol 2008, 194:62-69.

107. Finneran DJ, Nash KR: Neuroinflammation and fractalkine signaling in Alzheimer's disease. J Neuroinflammation 2019, 16:30.

108. Zhang X, Zhang M, Laties AM, Mitchell CH: Stimulation of P2X7 receptors elevates Ca2+ and kills retinal ganglion cells. Invest Ophthalmol Vis Sci 2005, 46:2183-2191. 
1227 109. Rodrigues-Neves AC, Aires ID, Vindeirinho J, Boia R, Madeira MH, Goncalves FQ, Cunha System of Microglial Cells. Front Pharmacol 2018, 9:16.

110. Zhang Y, Xu Y, Sun Q, Xue S, Guan H, Ji M: Activation of P2X7R- NLRP3 pathway in Retinal microglia contribute to Retinal Ganglion Cells death in chronic ocular hypertension

111. Bianchi BR LK, Touma E, Niforatos W, Burgard EC, Alexander KM, et al: Pharmacological (СОH). Exp Eye Res 2019, 188:107771.

112. Guttenplan KA, Stafford BK, El-Danaf RN, Adler DI, Munch AE, Weigel MK, Huberman AD,

113. Liddelow SA, Guttenplan KA, Clarke LE, Bennett FC, Bohlen CJ, Schirmer L, Bennett ML, Liddelow SA: Neurotoxic Reactive Astrocytes Drive Neuronal Death after Retinal Injury. Cell Rep 2020, 31:107776. characterization of recombinant human and rat $\mathrm{P} 2 \mathrm{X}$ receptor subtypes. Eur J Pharmacol 1999, 376:127-138. Munch AE, Chung WS, Peterson TC, et al: Neurotoxic reactive astrocytes are induced by activated microglia. Nature 2017, 541:481-487.

114. Sterling JK, Adetunji MO, Guttha S, Bargoud AR, Uyhazi KE, Ross AG, Dunaief JL, Cui QN: GLP-1 Receptor Agonist NLY01 Reduces Retinal Inflammation and Neuron Death Secondary to Ocular Hypertension. Cell Rep 2020, 33:108271.

115. Wang AYM, Wong VHY, Lee PY, Bui BV, Dudczig S, Vessey KA, Fletcher EL: Retinal ganglion cell dysfunction in mice following acute intraocular pressure is exacerbated by P2X7 receptor knockout. Sci Rep 2021, 11:4184. 
1248 116. Ortega F, Perez-Sen R, Delicado EG, Miras-Portugal MT: P2X7 nucleotide receptor is coupled to GSK-3 inhibition and neuroprotection in cerebellar granule neurons. Neurotox Res 2009, 15:193-204.

117. Monif M, Reid CA, Powell KL, Drummond KJ, O'Brien TJ, Williams DA: Interleukin-1beta has trophic effects in microglia and its release is mediated by P2X7R pore. $J$ Neuroinflammation 2016, 13:173.

118. Todd L, Palazzo I, Suarez L, Liu X, Volkov L, Hoang TV, Campbell WA, Blackshaw S, Quan N, Fischer AJ: Reactive microglia and IL1beta/IL-1R1-signaling mediate neuroprotection in excitotoxin-damaged mouse retina. J Neuroinflammation 2019, 16:118.

119. Sato A OH, Tsumuraya T, Song D, Ohara K, Asano M, Iwakura Y, Atsumi T, Shioda S: microglia/macrophages after spinal cord injury. J Neuroinflammation 2012, 9:65.

120. Liu J LW, Reigada D, Nguyen J, Laties AM, Mitchell CH: Restoration of Lysosomal pH in RPE Cells from Cultured Human and ABCA4-/- Mice: Pharmacologic Approaches and Functional Recovery. Invest Ophthalmol Vis Sci 2008, 49:772-780.

1263 121. Liu X, Nemeth DP, McKim DB, Zhu L, DiSabato DJ, Berdysz O, Gorantla G, Oliver B, Witcher

122. Fletcher EL, Wang AY, Jobling AI, Rutar MV, Greferath U, Gu B, Vessey KA: Targeting P2X7 receptors as a means for treating retinal disease. Drug Discov Today 2019, 24:1598-1605. 
Figure 1

Saline-injected BzATP-injected
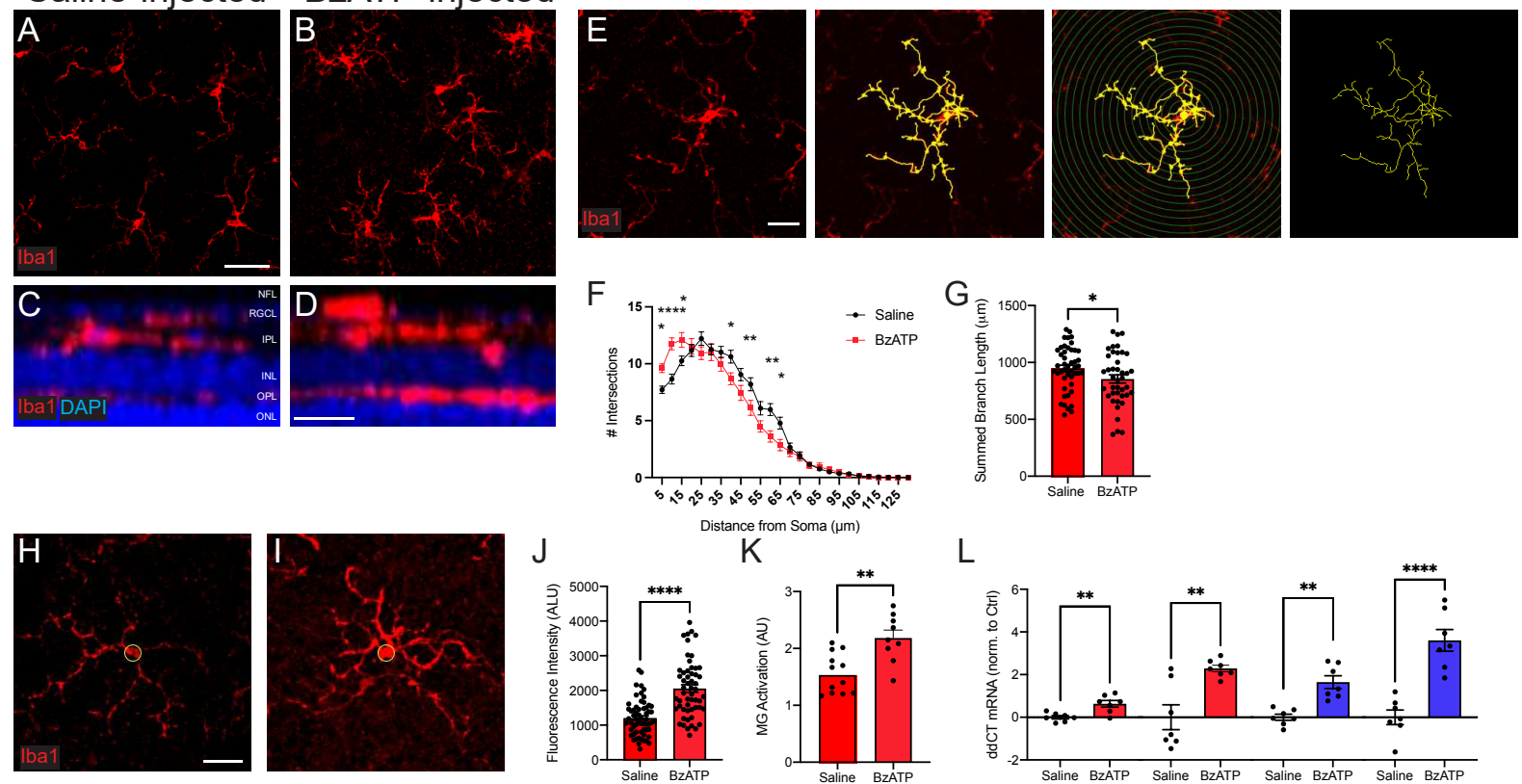

K

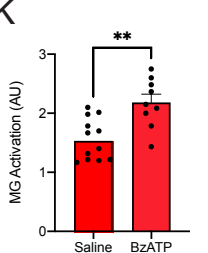

Saline-injected

BzATP-injected

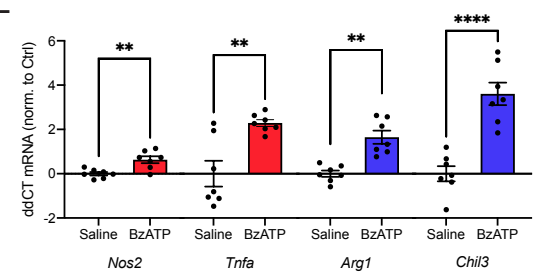


Figure 2
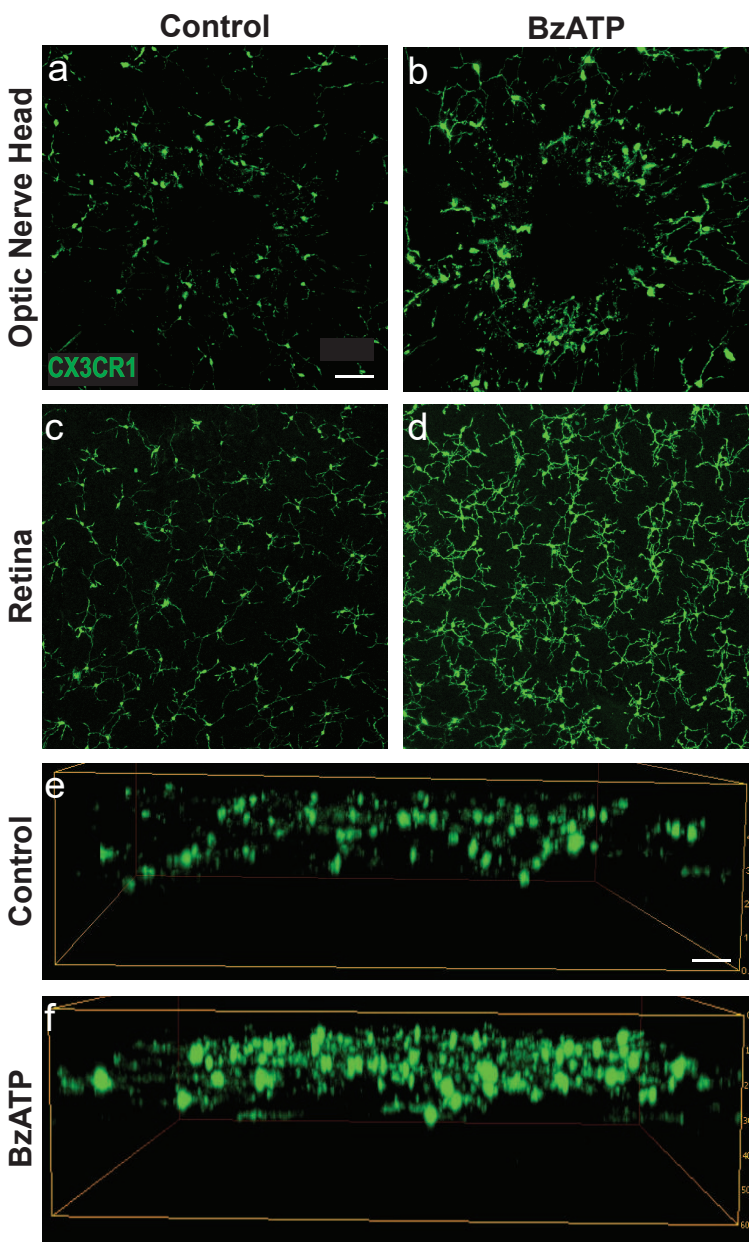


\section{Figure 3}

a
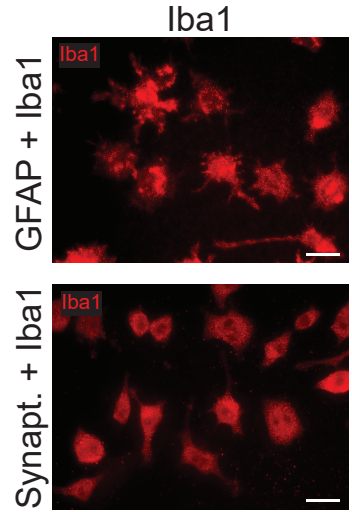

Iba1
GFAP
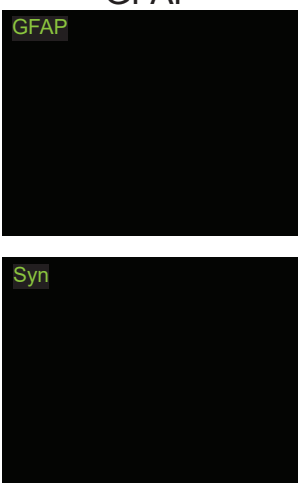

Synaptophysin
Hoechst
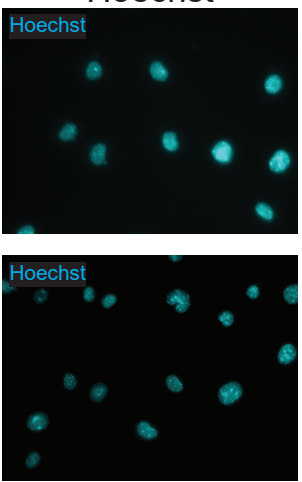

Hoechst
Merge
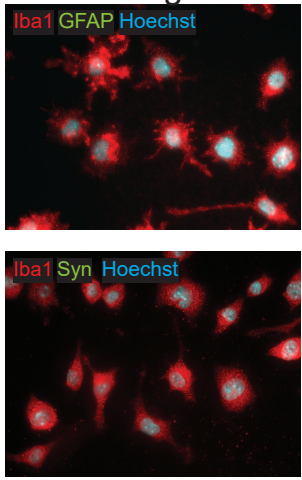

Merge

b

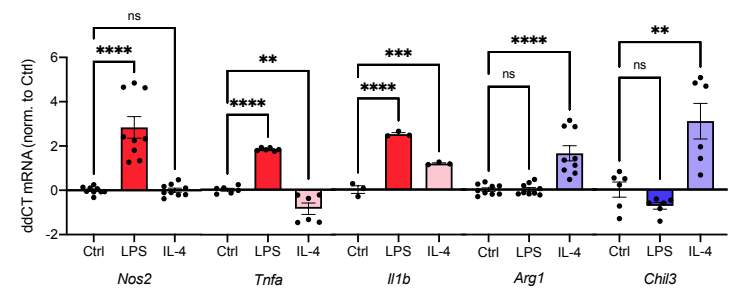

d

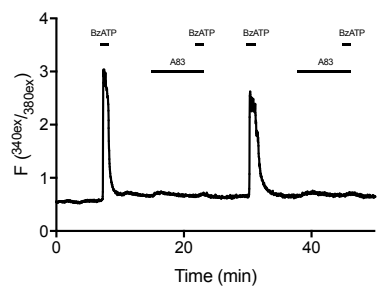

C
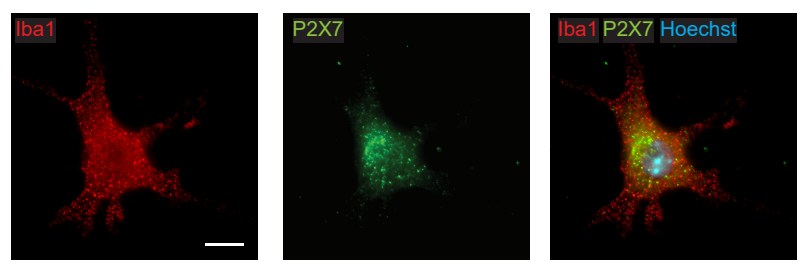

e

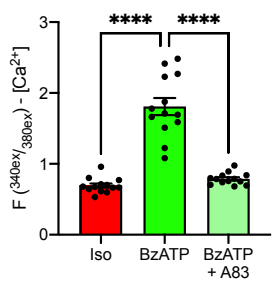


Figure 4
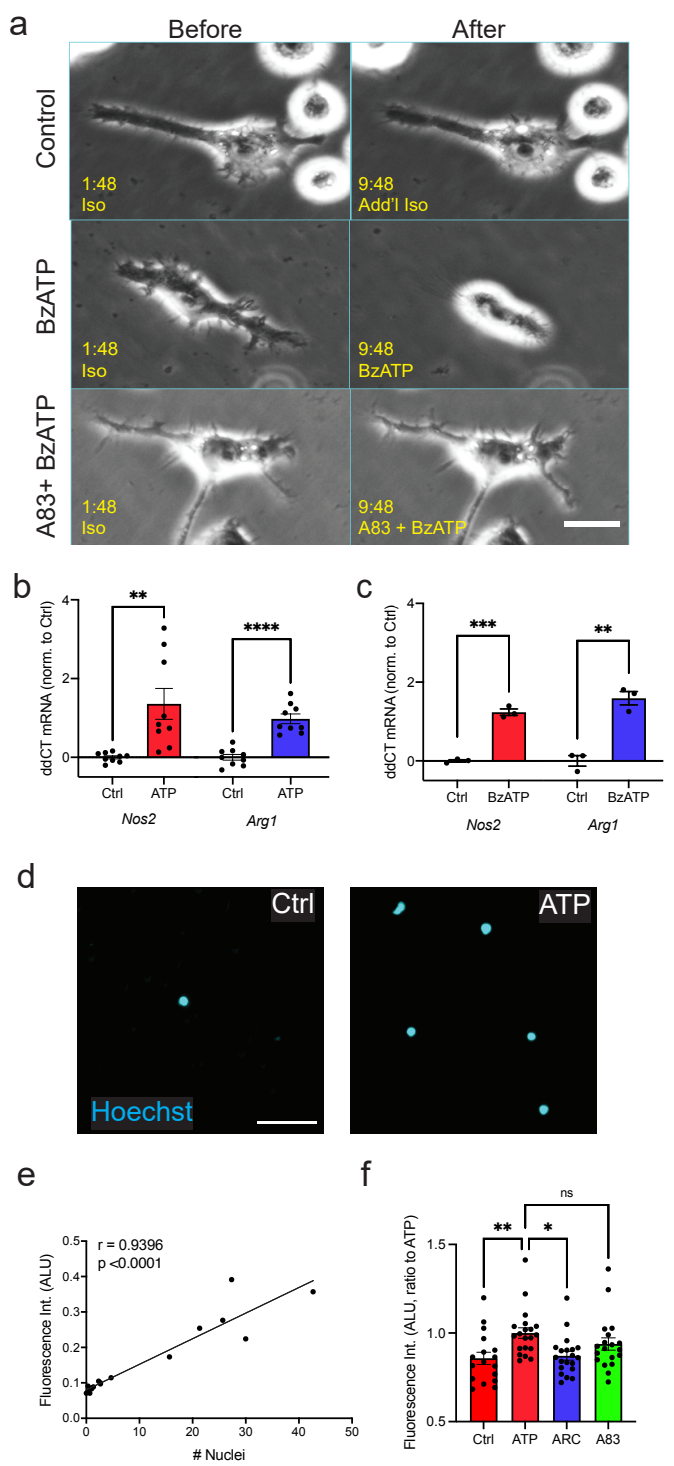
Figure 5

a

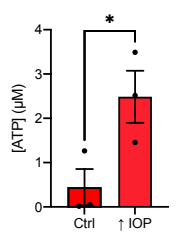

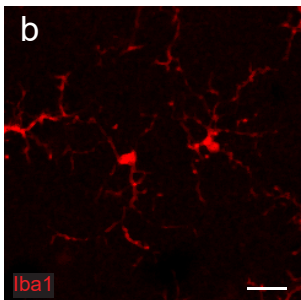

Ctrl

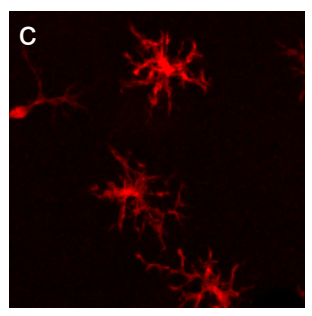

$\uparrow$ IOP d

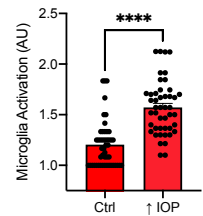

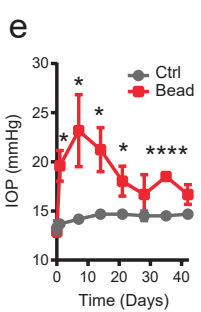

f
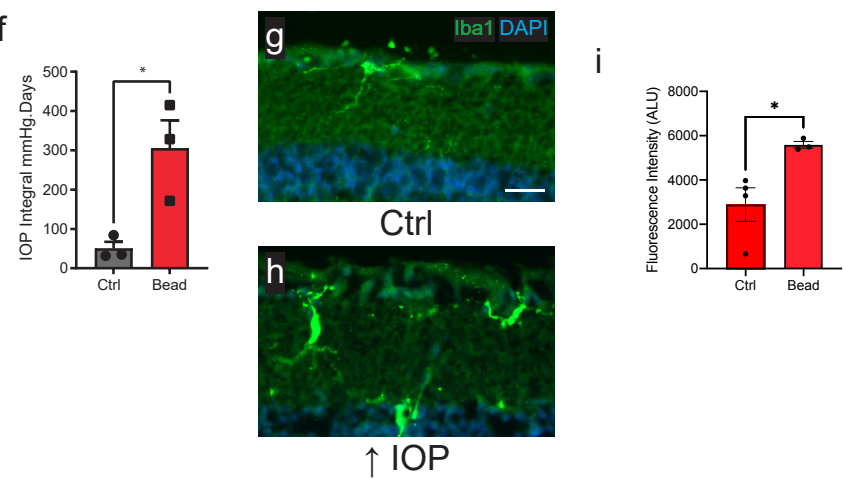

j

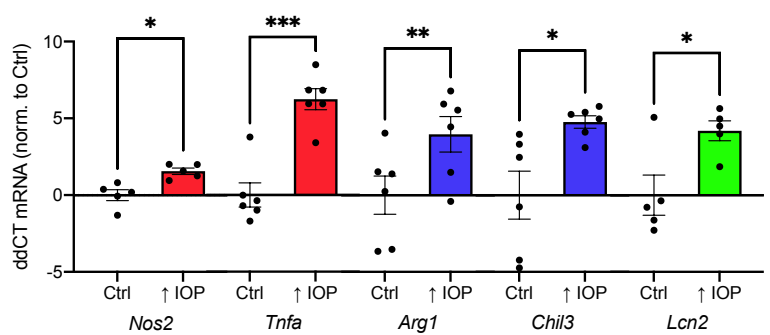


Figure 6

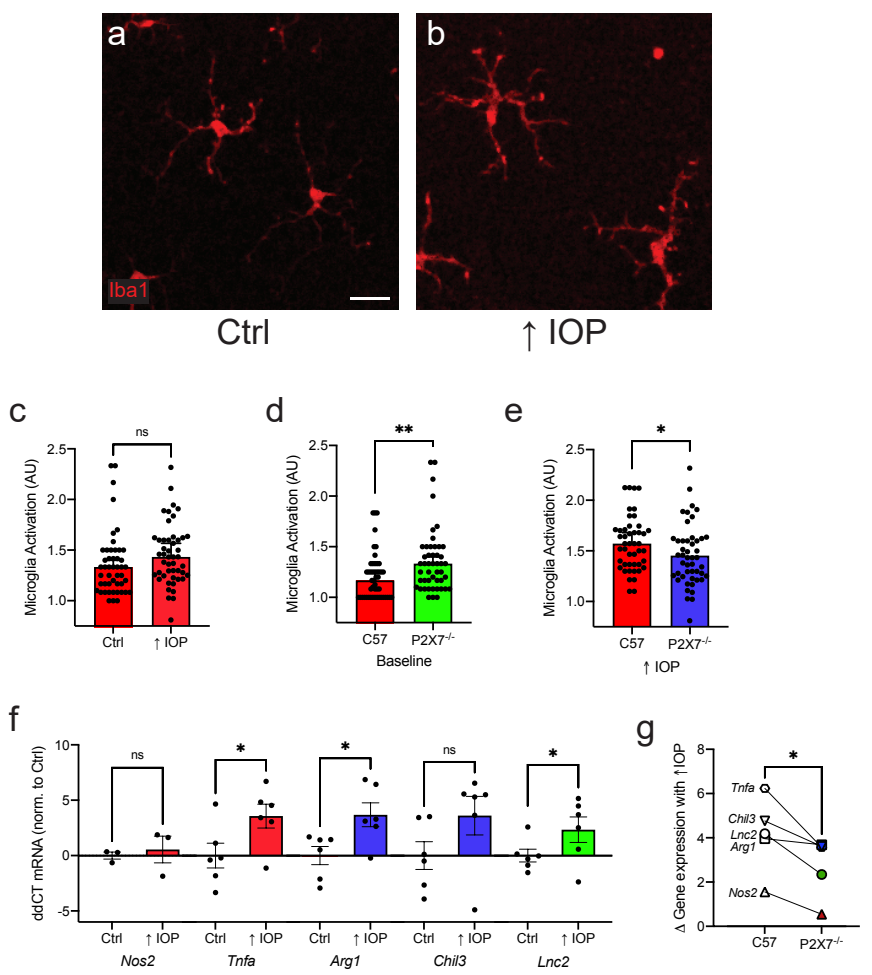


Figure 7
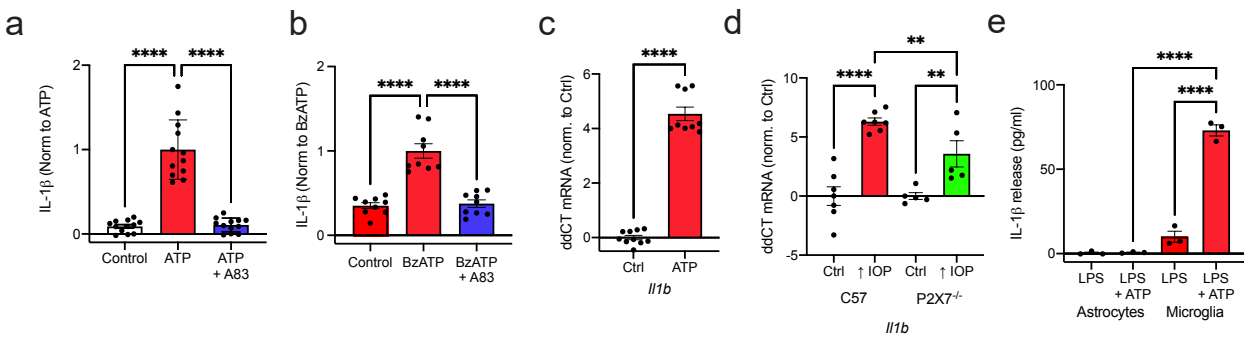


\section{Figure 8}

a

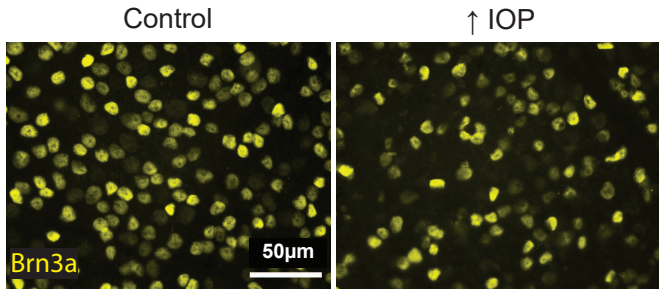

C57BI/6J

b

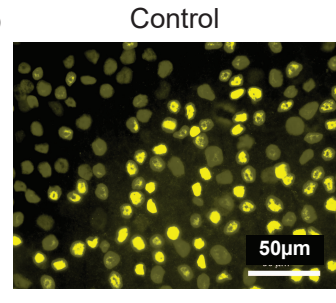

$\mathrm{P} 2 \times 7^{-1}$

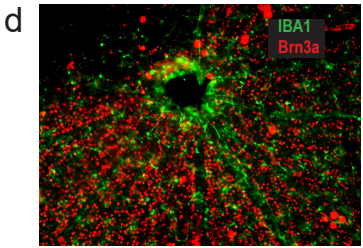

Center

e

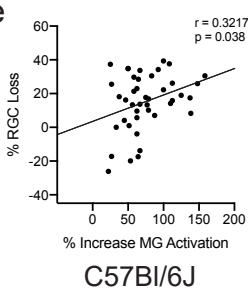

C57BI/6J
C
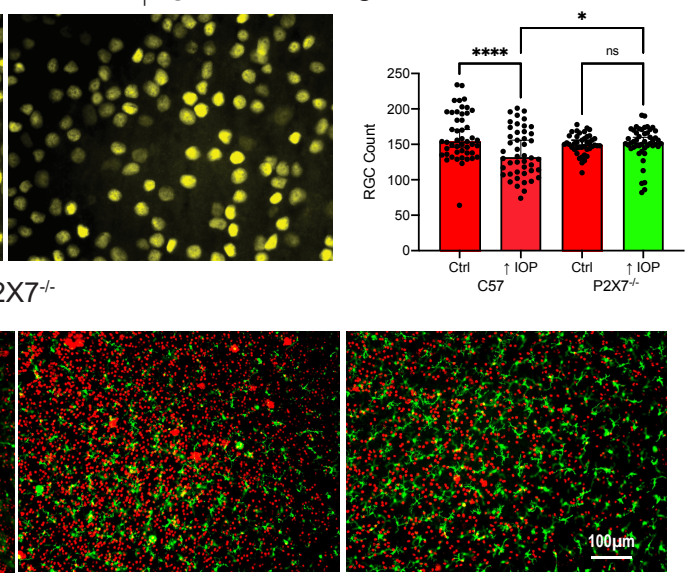

Middle

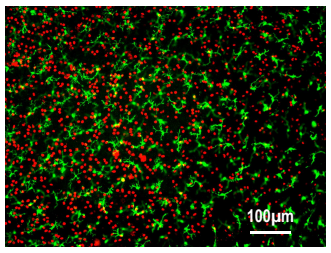

Periphery

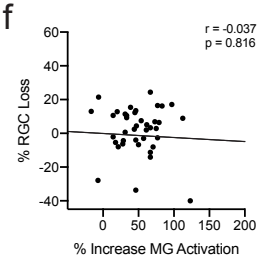

$\mathrm{P} 2 \times 7^{-1-}$ 
Supplementary figure 1: List of primers used for qPCR

\begin{tabular}{|c|c|c|c|c|}
\hline Gene Name & $\begin{array}{l}\text { GenBank } \\
\text { accession }\end{array}$ & Forward Primer (5'-3') & Reverse Primer (3'-5') & $\begin{array}{l}\text { Size } \\
\text { (bp) }\end{array}$ \\
\hline Nos2 & NM_010927.4 & CCCTTCAATGGTTGGTACATGG & ACATTGATCTCCGTGACAGCC & 158 \\
\hline Tnfa & NM_013693.3 & AAATGGCCTCССTCTCATCAG & GTCACTCGAATTTTGAGAAGATGATC & 73 \\
\hline $\operatorname{Arg} 1$ & NM_007482.3 & ACAAGACAGGGCTCCTTTCAG & GGCTTATGGTTACCCTCCCG & 148 \\
\hline Chil3 (cells) & NM_009892.3 & AGAAGGGAGTTTCAAACCTGGT & GTCTTGCTCATGTGTGTAAGTGA & 109 \\
\hline Chil3 (tissue) & NM_009892.3 & GAAGGAGCCACTGAGGTCTG & GAGCCACTGAGCCTTCAAC & 114 \\
\hline Len2 & NM 008491.1 & GGAACGTTTCACCCGCTTTG & TGAACCATTGGGTCTCTGCG & 140 \\
\hline GAPDH & NM 017008 & TCACCACCATGGAGAAGGC & GCTAAGCAGTTGGTGGTGCA & 169 \\
\hline
\end{tabular}




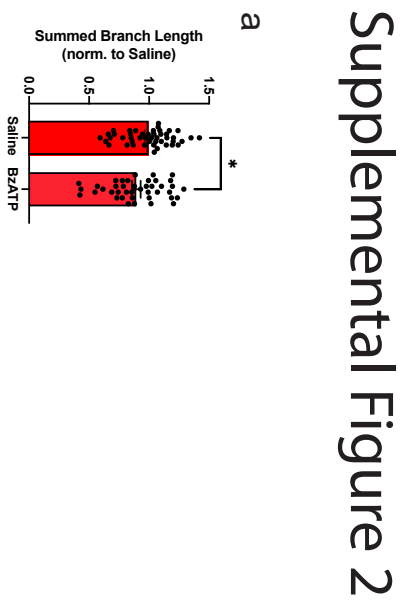




\section{Supplementary Figure 3.}

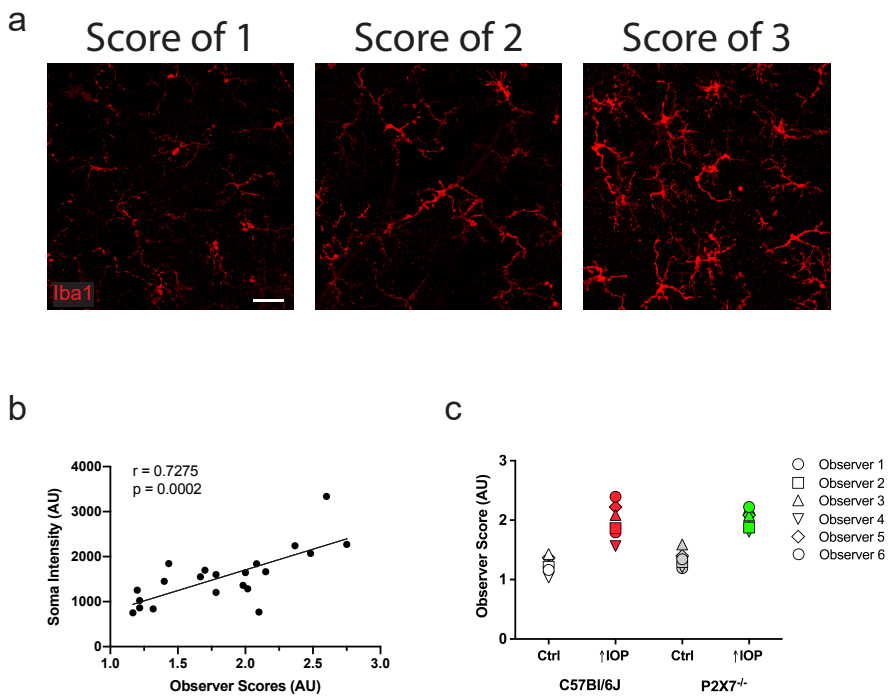


Supplementary Figure 5.

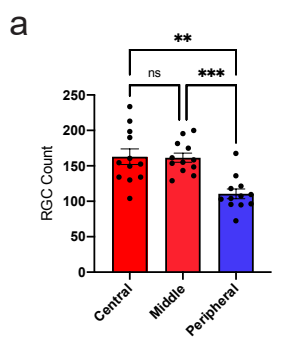

b

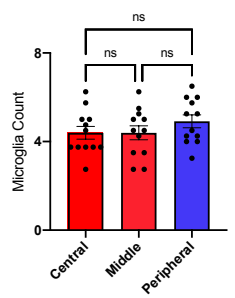




\section{Figures}

Saline-injected BzATP-injected
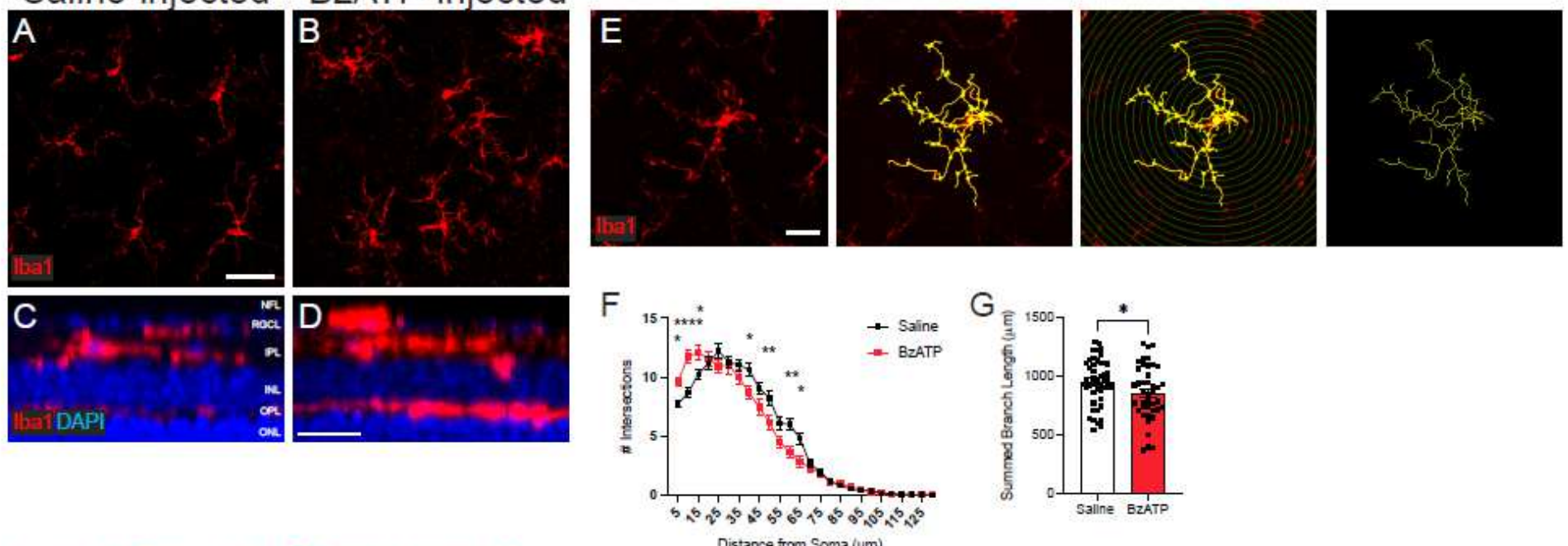

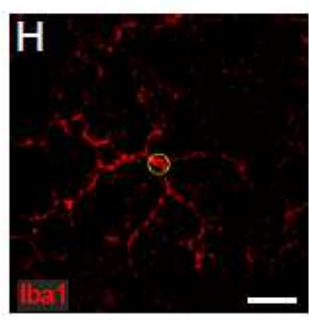

Saline-injected

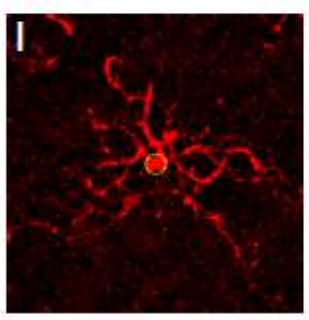

BzATP-injected

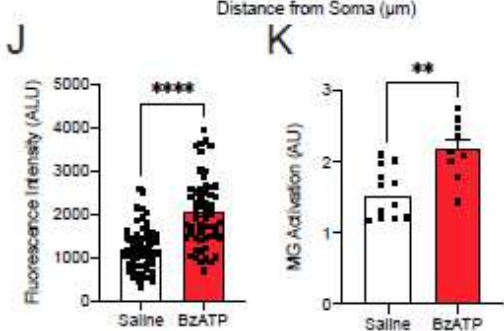

$\mathrm{L}$

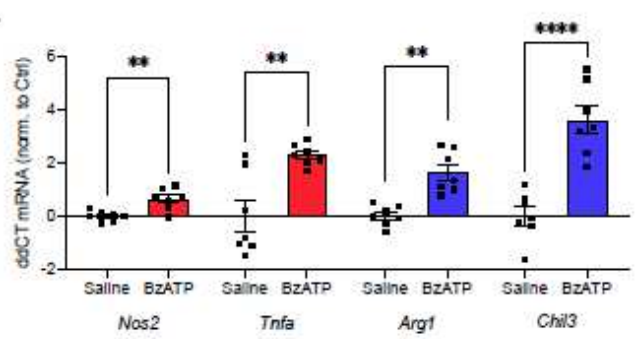

\section{Figure 1}

Retinal P2X7R stimulation leads to activated microglia morphology and gene expression. $a, b$ Retinae injected with Saline or $250 \mu \mathrm{M}$ BzATP indicated that BzATP exposure results in greater Iba1 expression and different morphology. c, d Z-projections of retina wholemounts demonstrate increased lba1 staining in the IPL and RGC layers of the retina with BzATP exposure. e. Representations of image tracing and conversion to a binary image for analysis. $\mathrm{f}$. Sholl analysis indicates reduced branching complexity of microglia exposed to BzATP ( $n=41,46$ cells, 3 biological replicates). $g$ Summed branch length is reduced in microglia exposed to BzATP. When compared to Saline (h), Cell soma size and Iba1 Intensity are elevated in circled area of microglia from retinae exposed to BzATP (i). j Quantification of Iba1 intensity in selected area ( $n=60,55$ cells, 3 biological replicates). k Observer scoring of images taken from Saline exposed or BzATP-exposed retinae supports data indicating that Iba1-positive microglia are activated upon exposure to BzATP. Each dot represents the mean value of 6 trained observers $(n=12,9$ images, 3 biological replicates). I Expression of classical activation genes Nos2, Tnfa, and alternative activation genes Arg1, Chil3 is elevated in retinae exposed to BzATP. Statistical significance shown at ${ }^{*} p<0.05$, ${ }^{\star \star} p<0.01,{ }^{* \star \star *} p<0.0001$. Scale bars represent $40 \mu \mathrm{m}(\mathrm{a}), 15 \mu \mathrm{m}(\mathrm{d}), 25 \mu \mathrm{m}(\mathrm{e}, \mathrm{f})$. 

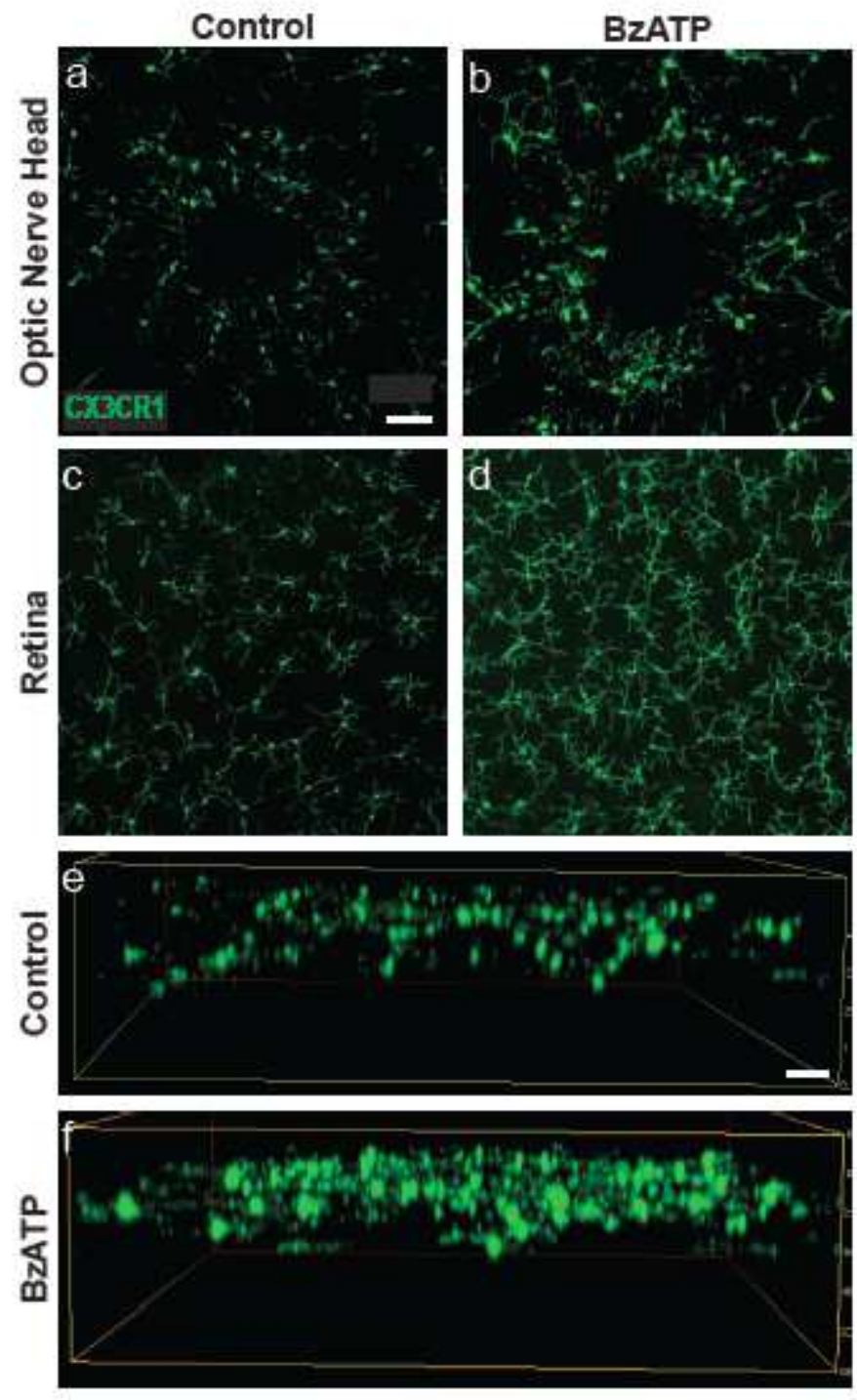

\section{Figure 2}

Ex vivo retinal wholemount P2X7R stimulation activates microglia. Retinal whole mounts isolated from Cx3CR1-GFP mice revealed increased fluorescence at the optic nerve head compared to control media (a) after exposure to $200 \mu \mathrm{M}$ BzATP for 2 hours (b). This elevation in fluorescence was also seen in the Middle Nasal areas when compared to control media (c) or after exposure to BzATP (c). d, e Z-projection of Middle-Nasal retinae exposed to control media or BzATP. Scale bar represents $50 \mu \mathrm{m}$. 
a

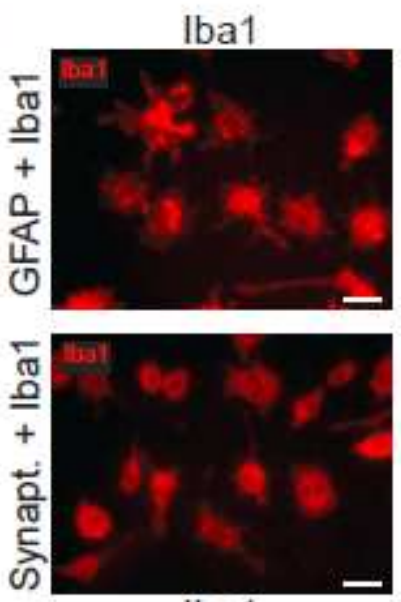

Iba1
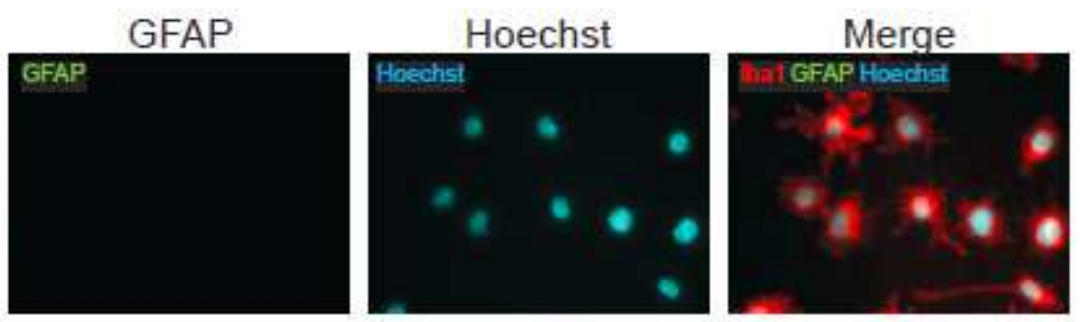

b

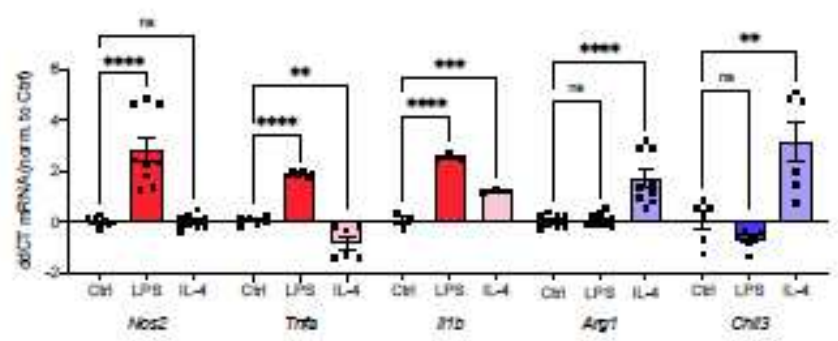

c

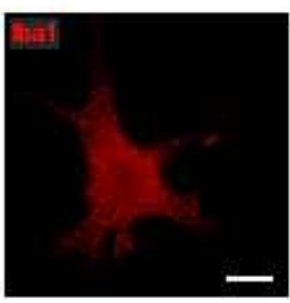

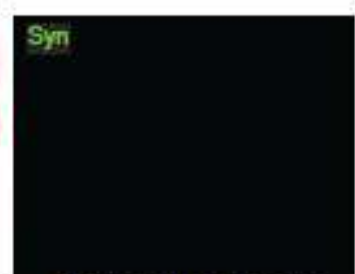

Synaptophysin

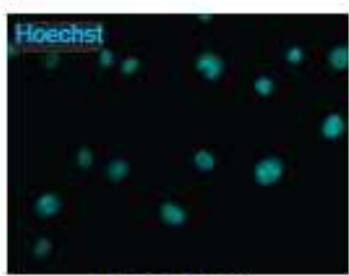

Hoechst

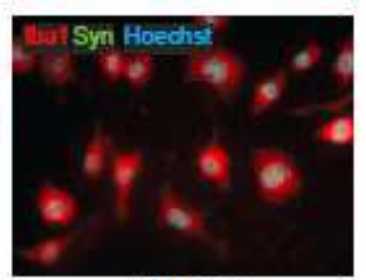

Merge
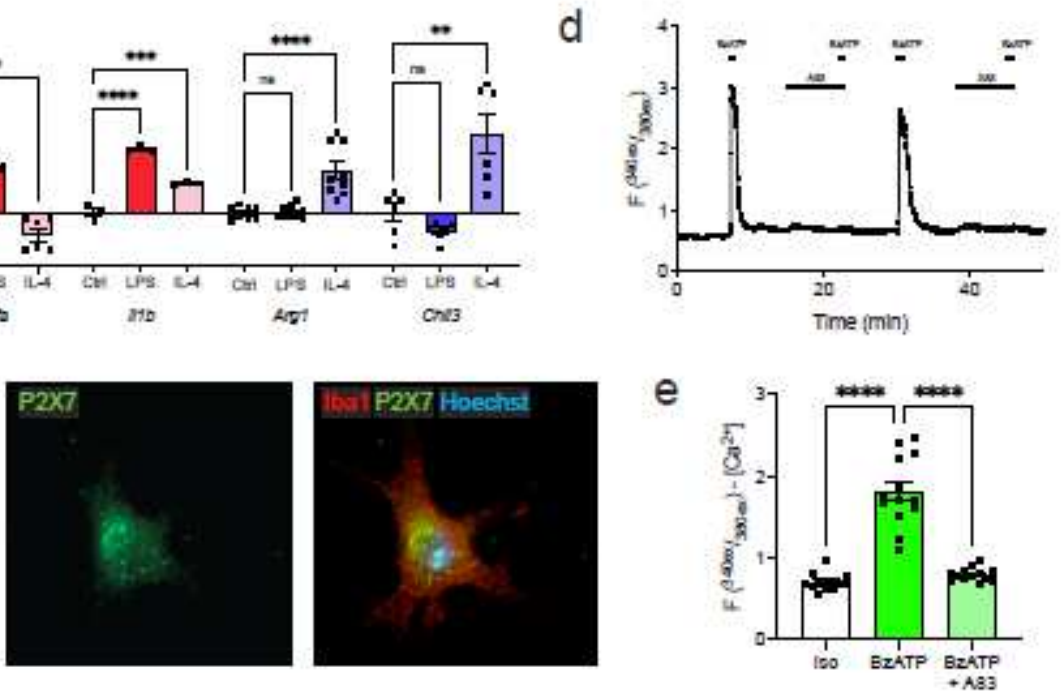

\section{Figure 3}

Isolated microglia express functional P2X7 receptor. a Immunocytochemistry indicating absence of GFAP or synaptohysin in primary cultures of retinal microglial cells. b qPCR results from cultured retinal microglial cells exposed for $4 \mathrm{hrs}$ to DMSO (Ctrl), $10 \mathrm{ng} / \mathrm{ml}$ LPS (LPS), or $10 \mathrm{ng} / \mathrm{ml} \mathrm{IL-4} \mathrm{(IL4),} \mathrm{with}$ changes in relative expression of mRNA for Nos2, Tnfa, Il1 b, Arg1, and YM1 were consistent with microglial cells polarization. ( $n=6-9$ samples from 2-3 biological replicates). $c$ Immunostaining indicated presence of P2X7 receptor in primary retinal microglial cells. $d$ Representative trace from a retinal microglia cell loaded with Fura-2 showing an elevation in the cytoplasmic $\mathrm{Ca} 2+$ levels in response to 1 min BzATP $(100 \mu \mathrm{M})$. The signal is displayed as the ratio of light excited at $340 / 380 \mathrm{~nm}$ and emitted > $520 \mathrm{~nm}$. The response to BzATP was reduced with exposure to $1 \mu \mathrm{M}$ antagonist A839977 (A83) but restored upon wash out. e Quantification of the increase in the ratio of light excited at $340 \mathrm{~nm}$ vs. $380 \mathrm{~nm}$, em $>520 \mathrm{~nm}$ (referred to as "F $340 / 380$ "), indicative of cytoplasmic calcium in cells loaded with Fura-2 $\left(n=3-6\right.$ cells/replicate, 3 biological replicates. Statistical significance shown at ${ }^{* \star} p<0.01,{ }^{\star \star \star} p<0.001$, $\star * \star * p<0.0001$. Scale bar represents $20 \mu \mathrm{m}$ (a), and $10 \mu \mathrm{m}$ (c). 
a
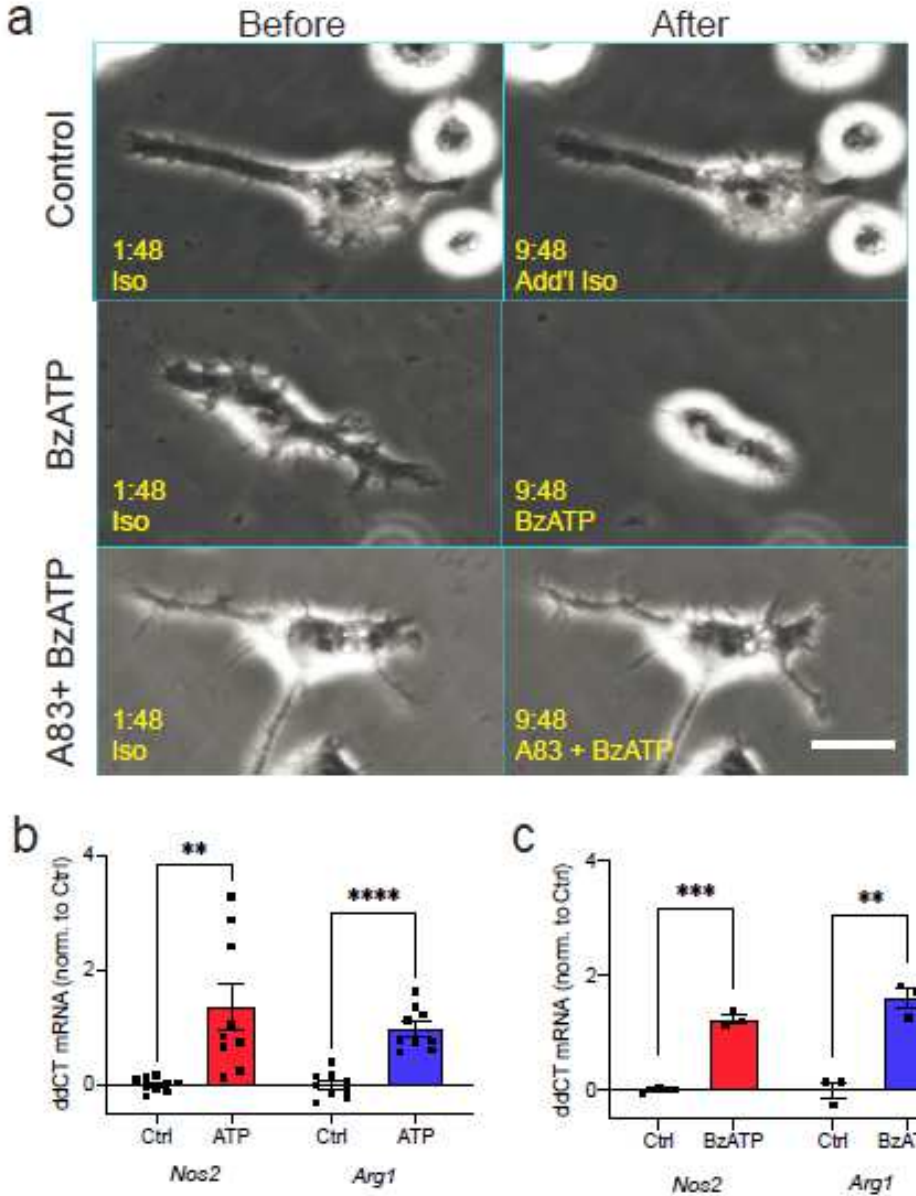

C

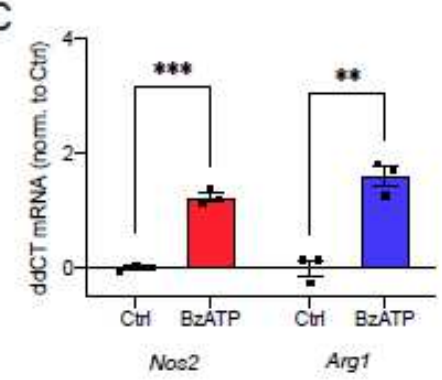

d
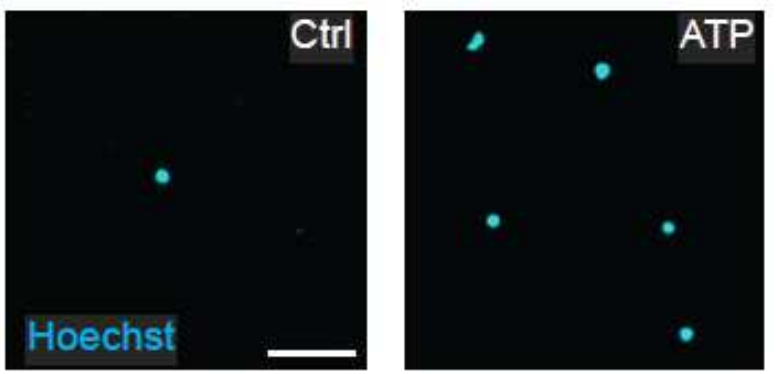

e

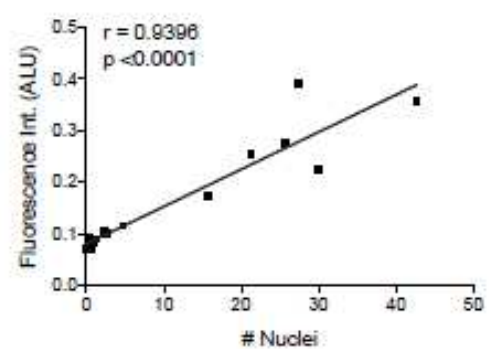

f

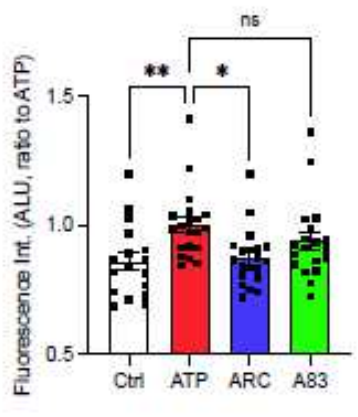

Figure 4

Isolated retinal microglia respond to P2X7 receptor stimulation with activation and retraction a Images taken before and after application of isotonic solution (Control), $250 \mu \mathrm{M}$ BzATP or $250 \mu \mathrm{M}$ BzATP + 10 $\mu \mathrm{M}$ A839977 (A83). In cells preincubated with $10 \mu \mathrm{M}$ A839977, BzATP did not alter cell size much. Similar responses were found in $>7$ experiments. b Elevated expression of classical activation marker Nos 2 and alternative activation marker Arg1 in cultured retinal microglial cells exposed to 1 mM ATP for 4 hrs ( $\mathrm{n}=9$ 10 samples, 3 biological replicates). c Similar gene expression changes were observed when microglial cells were exposed to $200 \mu \mathrm{M}$ BzATP for 4 hrs ( $n=3$ tests, 1 biological replicate). d Representative images of migration 2-part Boyden chamber kit filter indicated that microglia migrate towards a 1 mM ATP gradient. e Microglia were isolated from murine brain and subjected to migration. Correlation between number of Hoechst-stained nuclei per well and fluorescence at 340ex/527em (Pearson's correlation $r=0.9396$ with $p=0.0001)$. $f$ Microglia migration to $1 \mathrm{mM}$ ATP was inhibited with preexposure to $10 \mu \mathrm{M}$ P2Y12 inhibitor AR-C 69931 (ARC) but not $1 \mu$ M P2X7-inhibitor A83 ( $n=17-20$ samples, 4 biological replicates). Statistical significance shown as ${ }^{*} p<0.05,{ }^{* *} p<0.01,{ }^{* *} p<0.001,{ }^{*} * \star x<0.0001$. Scale bars represent $10 \mu \mathrm{m}$ (a), $50 \mu \mathrm{m}$ (d). 

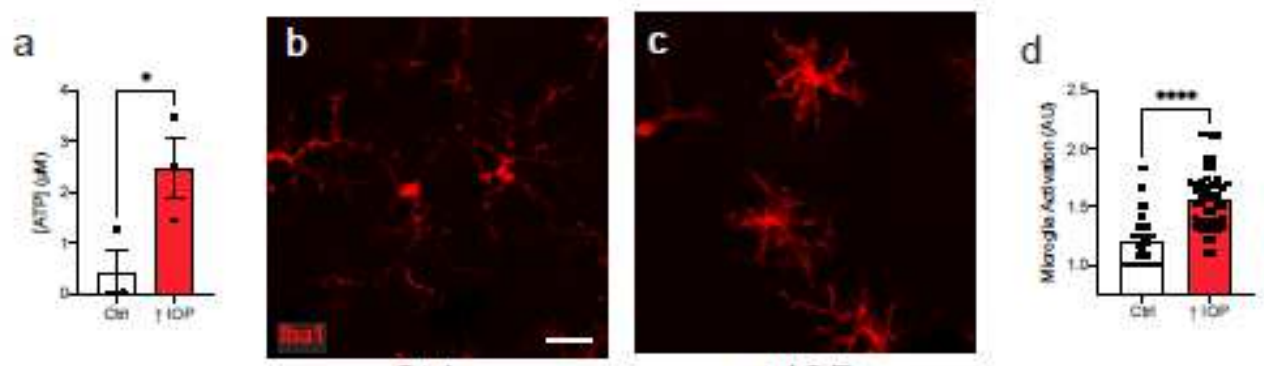

Ctrl

$\uparrow 1 \mathrm{OP}$
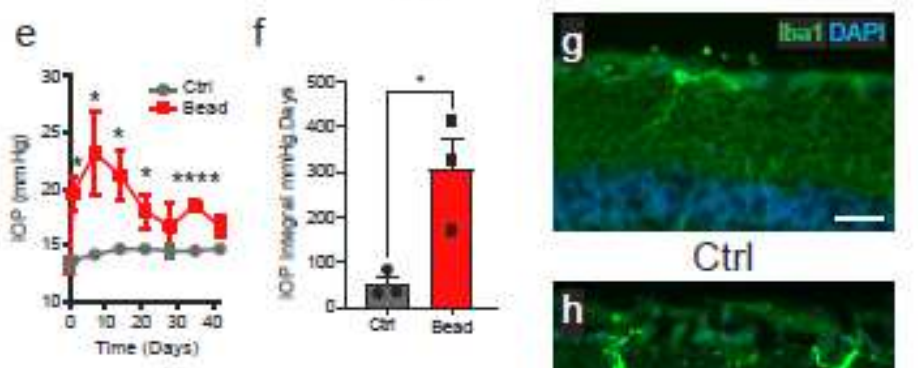

Ctrl
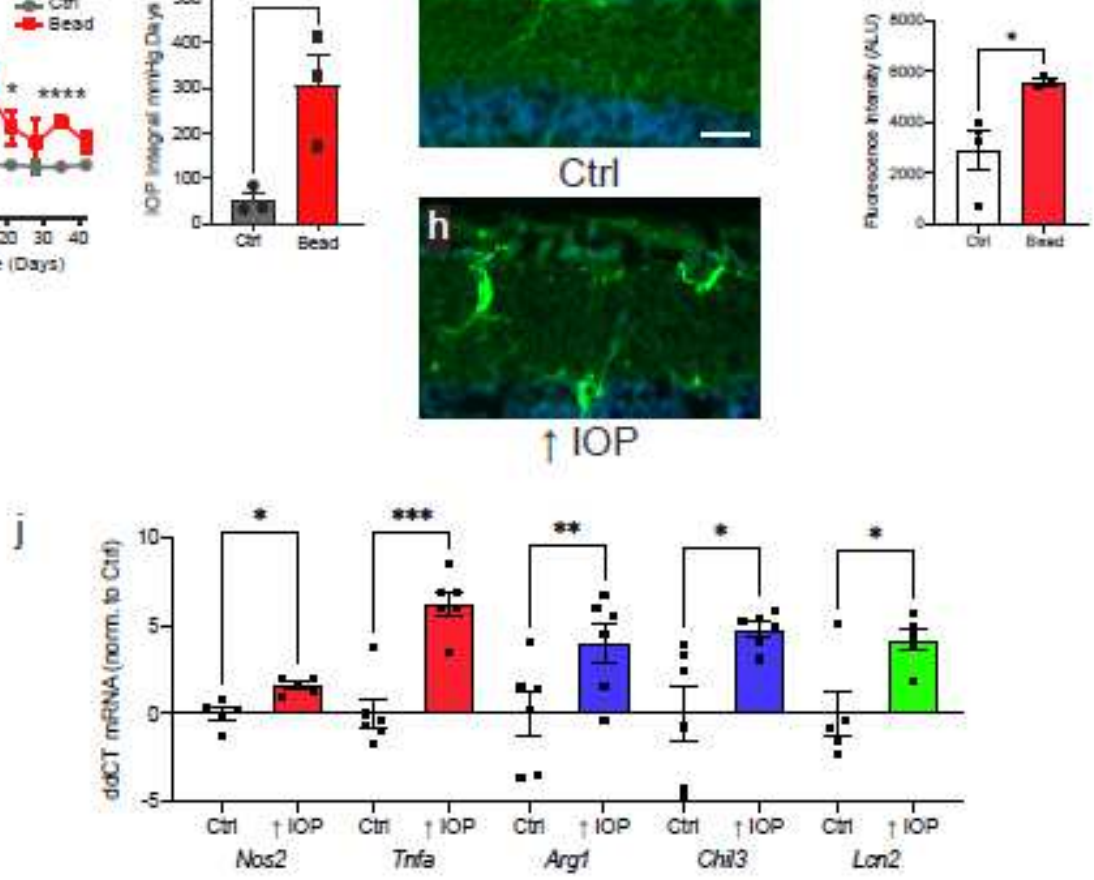

\section{Figure 5}

Elevation of IOP releases ATP and activates microglia. a Increase in ATP concentration of vitreous humor $24 \mathrm{hrs}$ after elevation of IOP via the controlled elevation of IOP (CEI) procedure ( $n=3$ biological replicates). $\mathrm{b}$ Immunohistochemical image showing staining for Iba1 (red) in the central nasal quadrant in a retinal whole mount from an unstimulated C57BI/6J mouse eye. c lba1 staining from an analogous region of an eye after elevation of IOP, and sacrificed 24hrs later. Retinal microglia subject to IOP elevation showed increased soma s 845 ize, increased staining for Iba1, and shorter, thicker projections. d Quantification of morphological activation of microglia across central and middle regions $(n=48,47$ images, 3 biological replicates). e Weekly IOP measurements from mice injected with magnetic beads or saline control $(n=3)$. $f$ IOP integral, expressed as summed $\mathrm{mmHg}$ days exposure over baseline IOP, for bead and saline-injected eyes. $\mathrm{g}$ Immunohistochemical staining of Iba1 of a cryosection of the central region of saline injected eye outlines elongated processes. $\mathrm{h}$ lba1 staining of an analogous region of a retina subjected to 7 weeks of elevation of IOP indicates microglial phenotype emblematic of activation. i Quantification of a $5 \mu \mathrm{m}$ area surrounding the soma indicates significant elevation of Iba1 intensity per cell ( $n=4$ retinae, 3 mice). $j$ qPCR showing increased expression of Nos2, Tnfa, Arg1, and Chil3, as was Lcn2 in the retina 24 hrs after 
the $\mathrm{CEI}$ procedure. Dots represent change in expression from a single mouse, with expression normalized to the average of unpressurized contralateral eyes ( $n=4-7$ mice). Scale bars represent $20 \mu \mathrm{m}(\mathrm{b})$ and 50 $\mu \mathrm{m}(\mathrm{g})$. Statistical significance shown as ${ }^{*} \mathrm{p}<0.05,{ }^{* *} \mathrm{p}<0.01,{ }^{*} * \star * \mathrm{p}<0.0001$.

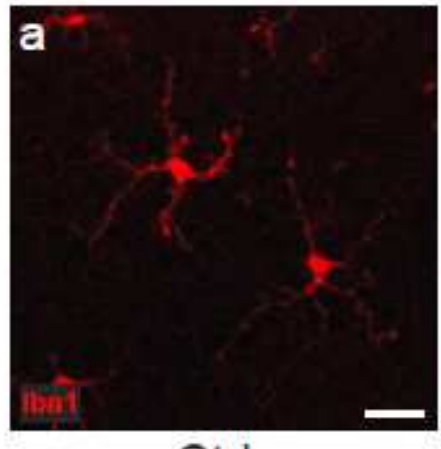

Ctrl
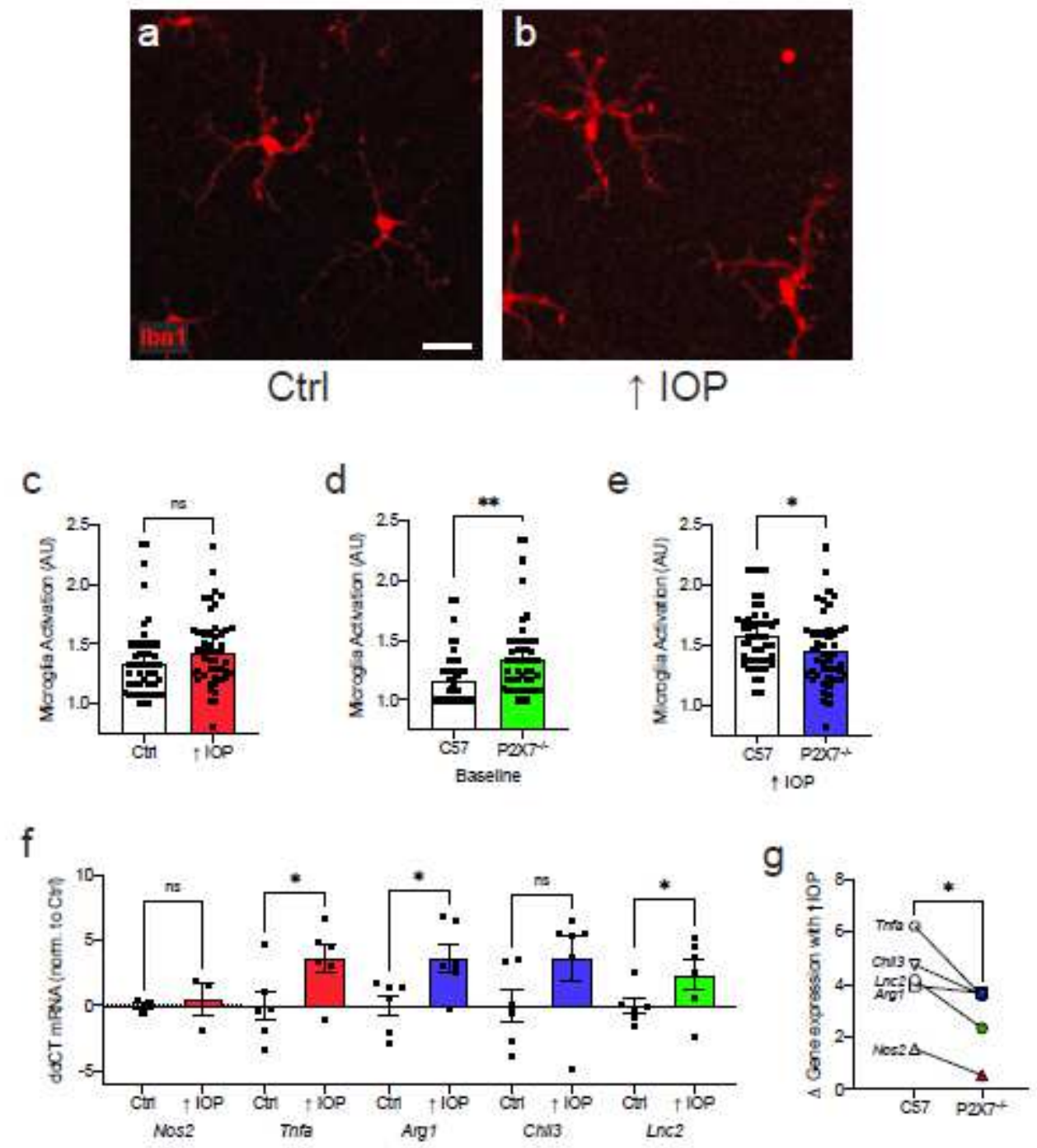

\section{Figure 6}

$\mathrm{P} 2 \mathrm{X} 7$ receptor is implicated in microglia activation in vivo. a lba1 staining central nasal quadrant retinal whole mount of P2X7-/- mouse under baseline conditions. b Immunohistochemical staining of an analogous region $24 \mathrm{hrs}$ after IOP elevation in P2X7-/- mice. c Observer scoring of IHC images of microglial morphology across central and middle regions of P2X7-/- mice suggests no differences between baseline (clear) and CEI (red) ( $n=48$ images, 3 mice). $d$ Scoring of baseline conditions was greater in retina from P2X7-/- mice (green) than C57BI6J mice (clear) ( $n=48$ images, 3 mice). e $24 \mathrm{hrs}$ after elevation of IOP, microglial activation scores were greater in C57 mice than P2X7-/- mice (3 Ctrl, 3 P2X7-/- mice). $f$ Increase in retinal expression of Arg1, TNFa, iNOS, Chil3 and Lcn2 found 24 hrs after the CEl procedure in P2RX7-/- mice ( $n=3-6$ mice). $g$ Relative change in retinal expression of key genes after the $\mathrm{CEI}$ procedure in $\mathrm{C} 57 \mathrm{BI} / 6 \mathrm{~J}$ mice compared to P2RX7-/- mice. Values represent mean $\triangle \Delta \mathrm{CT}$ levels for 
each gene compared to unpressurized control retinae. Scale bar represents $20 \mu \mathrm{m}$. Statistical significance shown as ${ }^{*} p<0.05, * * p<0.01$.

a

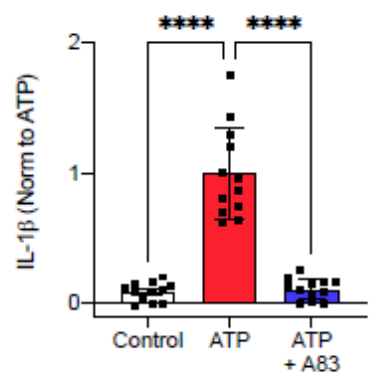

b

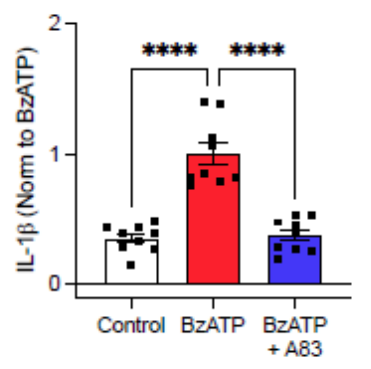

C

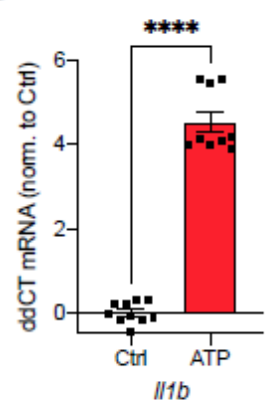

d

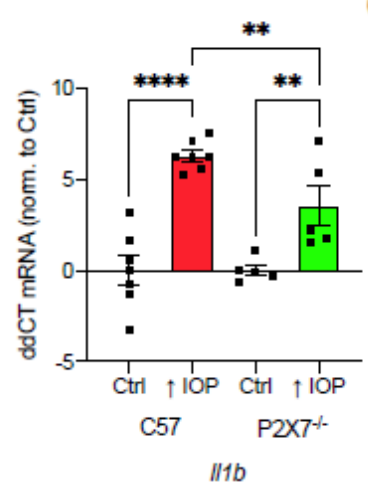

e

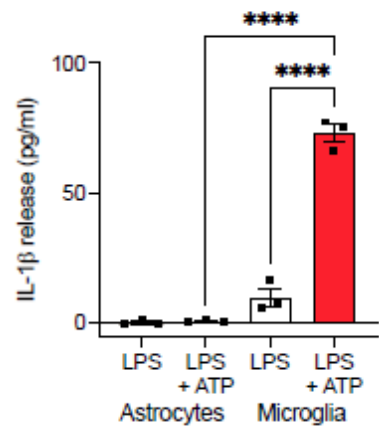

Figure 7

P2X7 receptor stimulation releases cytokine IL-1 $\beta$. a Mouse retinal microglial cells primed with $1 \mu \mathrm{g} / \mathrm{ml}$ LPS for three hours then exposed to an additional 3 mM ATP released a significant quantity of IL-1 $\beta$ protein into the supernatant relative to LPS alone (Control). Preincubation with $1 \mu \mathrm{M}$ A83 abolished release ( $\mathrm{n}=12$ samples, 4 biological replicates). b Similar pattern of IL-1 $\beta$ release was measured in primed microglial cells with $1 \mathrm{hr}$ exposure to $200 \mu \mathrm{M}$ BzATP ( $n=9$ samples, 3 biological replicates). c Gene expression of $111 \mathrm{~b}$ was elevated in cultured mouse retinal microglia after $4 \mathrm{hr}$ exposure to $1 \mathrm{mM}$ ATP. $\mathrm{d}$ Gene expression of II1b was upregulated in C57B67 and P2X7-/- retinae after elevated IOP, but that upregulation was significantly less in P2X7R-/- retinae ( $n=6,5$ mice). e Rat microglia primed with 500 $\mathrm{ng} / \mathrm{ml}$ LPS for 3 hours followed by exposure to an additional $3 \mathrm{mM}$ ATP released significantly more IL-1 $\beta$ than cultured rat astrocytes primed with LPS and $5 \mathrm{ng} / \mathrm{ml} \mathrm{IL-1a}$, followed by similar exposure to ATP ( $\mathrm{n}=3$ samples from cultures obtained from multiple rats combined ). Statistical significance shown as ${ }^{*} p<0.05$, $\star \star \star \star x p<0.0001$. 
a

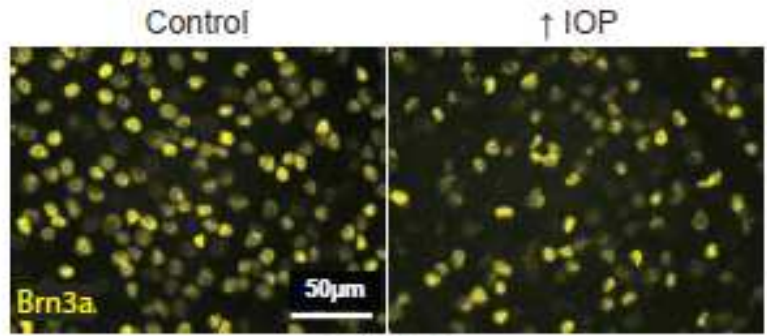

C57Bl/6J

b

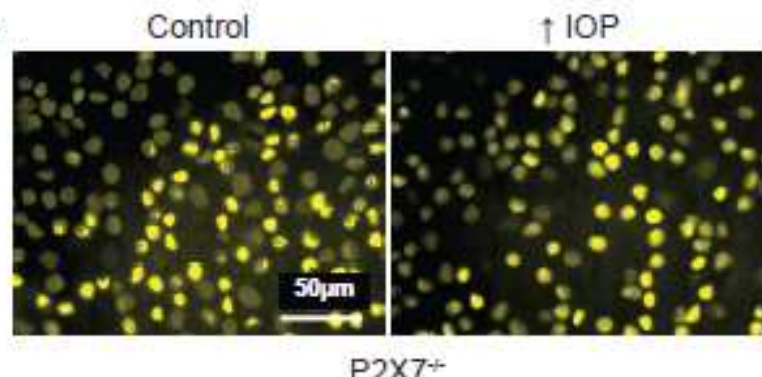

c

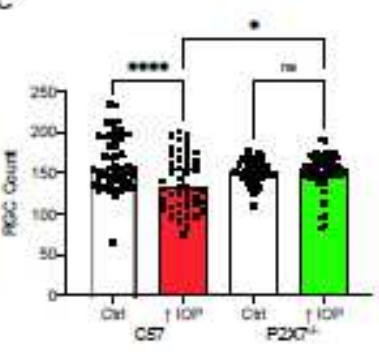

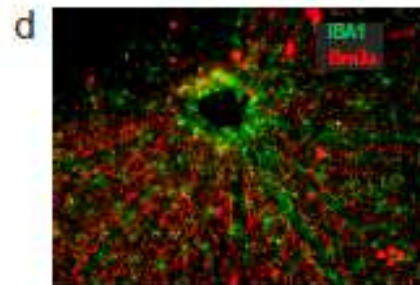

Center

e

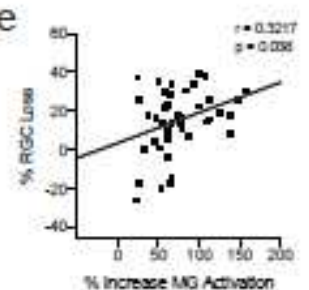

C57BI/6J

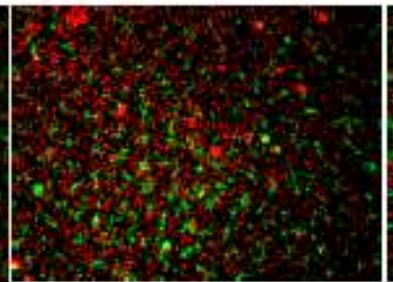

Middle

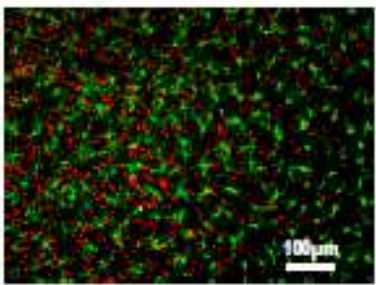

Periphery

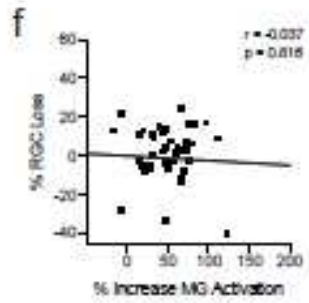

$\mathrm{P} 2 \times 7^{++}$

\section{Figure 8}

Ganglion cell death is correlated to P2X7R stimulation and 888 microglial activation. a Representative images show that staining for RGC marker Brn3a is decreased in retina 22 - 24 hrs after IOP elevation following IOP elevation to control C57BI/6J mice. b Decrease in Brn3a staining was not observed in retinae from P2X7- \- after IOP elevation compared to control. c Fewer Brn3a-labeled RGCs were counted in retinae from $\mathrm{C57BI} / 6 \mathrm{~J}$ eyes exposed to elevated IOP (red) compared to normotensive controls (clear, left). RGC numbers in control (clear, right) and elevated IOP (green) in P2X7-/- mice were unchanged, demonstrating that there is no pressure dependent loss of RGCs in the P2X7-/- mice. More Brn3a cells were quantified from P2X7-/- eyes subjected to elevated IOP (green) compared to C57 eyes (red) (n= 4246 images, 3 mice). d Retinal whole mount from a C57BI/6J mouse showing the spatial relationship between RGCs stained with Brn3a (red) and lba1 stained microglial (green); images show staining across the central region with the optic nerve head (left) the middle region (center) and peripheral region (right) of the optic disk are shown. e Correlation between the loss of RGCs and rise in microglial activation 
accompanying IOP elevation. (Pearson's correlation with $p=0.038 ; n=7$ sections from central and middle regions of 3 control and contralateral CEl retina). $f$ No such correlation between RGC loss and microglial activation exists in regions from P2X7-\- mice. Statistical significance show as ${ }^{\star} p<0.05,{ }^{\star \star \star *} p<0.0001$.

\section{Supplementary Files}

This is a list of supplementary files associated with this preprint. Click to download.

- ExtractPage.pdf

- FigS4aControllsojpegcompressed.avi

- FigS4bBzATPjpegcompressed.avi

- FigS4cA83Bzjpegcompressed.avi 